This is a peer-reviewed, accepted author manuscript of the following research article: Rao, X., Zhang, F.,

Lu, Y., Luo, X., \& Chen, F. (Accepted/In press). Surface and subsurface damage of reactionbonded silicon carbide induced by electrical discharge diamond grinding. International Journal

of Machine Tools and Manufacture. https://doi.org/10.1016/j.ijmachtools.2020.103564

\title{
Surface and subsurface damage of reaction-bonded silicon carbide induced by electrical discharge diamond grinding
}

Abstract: Reaction-bonded silicon carbide (RB-SiC) ceramic, one of the best candidates for large optical mirrors, is difficult to machine because of its high hardness and brittleness. A hybrid process called electrical discharge diamond grinding (EDDG) exhibits potential for improving the machinability of RB-SiC by combining electrical discharge machining (EDM) and diamond grinding. However, this hybrid process leads to damages that differ from those in conventional processes owing to the simultaneous actions of EDM and diamond grinding. In the present study, surface and subsurface damages induced by the interactions between EDM and diamond grinding during the EDDG of RB-SiC were examined. The effect of the discharge energy was considered. The surface and subsurface topographies and microstructures were characterized via scanning electron microscopy, Raman spectroscopy, and transmission electron microscopy. The EDM and grinding zones exhibited distinctive surface topographies and different dominant material removal mechanisms. An increase in the discharge energy facilitated ductile removal of the material and decomposition of SiC. Thus, a thinner subsurface damage layer was obtained compared with that in the less-thermally affected zone. The decomposed $\mathrm{C}$ and material migration tended to increase with the discharge energy. Owing to the interactions between EDM and diamond grinding, the subsurface was a mixture of amorphous/crystalline C, polycrystalline/nanocrystalline 
This is a peer-reviewed, accepted author manuscript of the following research article: Rao, X., Zhang, F.,

Lu, Y., Luo, X., \& Chen, F. (Accepted/In press). Surface and subsurface damage of reactionbonded silicon carbide induced by electrical discharge diamond grinding. International Journal of Machine Tools and Manufacture. https://doi.org/10.1016/j.ijmachtools.2020.103564

$\mathrm{SiC}$, and a crystalline SiC matrix.

Keywords: subsurface damage; electrical discharge diamond grinding; reactionbonded silicon carbide; phase transformation; material migration

\section{Introduction}

Reaction-bonded silicon carbide ( $\mathrm{RB}-\mathrm{SiC})$ is one of the best candidate materials for the fabrication of large-scale optical mirrors owing to its high specific stiffness and surface shape stability [1]. However, its hardness makes it difficult to machine RB-SiC into the desired shapes, e.g., planar, spherical, aspheric, and free-form surfaces [2], with high efficiency via the conventional grinding process. Additionally, efficient grinding of large-scale RB-SiC mirrors faces the problems of serious clogging and wear of the metal-bonded grinding wheel $[3,4]$. To solve these problems, a hybrid process called electrical discharge diamond grinding (EDDG) has been employed for grinding RBSiC by introducing electrical discharge machining (EDM) [5]. Owing to the effects of the discharge-induced erosion on the metal bonds of the grinding wheel and the workpiece, this process has the advantages of reduced grinding force [6], improved material removal rate [7,8], and effective declogging of the wheel surface [9]. However, EDM can generate a temperature of up to $8000-10000{ }^{\circ} \mathrm{C}$ at the center of the plasma $[10,11]$, causing melting/vaporization of the material and affecting the diamond grinding of this process via thermal transmission. EDDG allows material removal through the interaction between EDM and diamond grinding. Therefore, the surface and subsurface damage is significantly different from that resulting from the individual 
This is a peer-reviewed, accepted author manuscript of the following research article: Rao, X., Zhang, F.,

Lu, Y., Luo, X., \& Chen, F. (Accepted/In press). Surface and subsurface damage of reactionbonded silicon carbide induced by electrical discharge diamond grinding. International Journal of Machine Tools and Manufacture. https://doi.org/10.1016/j.ijmachtools.2020.103564

processes of EDM and diamond grinding.

Surface and subsurface damage has been widely investigated in the machining of SiC materials, as it is directly related to the surface integrity, particularly for EDM. Melting and evaporating the workpiece material allows EDM to be employed for drilling [12], milling [13,14], cutting [15], and slicing [16] of SiC irrespective of its hardness. Although an increasing machining rate and reduced tool wear have been achieved via parameter optimization $[15,17,18]$, surface and subsurface damage is inevitable in EDM of SiC, owing to the discharge-induced thermal energy. Thermal energy was suggested to be a main material removal mechanisms in EDM of SiC, and it causes surface damages such as cracks, pores, and rectangular pits [15]. EDM predominantly decomposed $\mathrm{SiC}$ and formed $\mathrm{Si}, \mathrm{C}$, and cracks [16]. An extra layer over the top of the original surface and a porous layer with plenty of voids underneath was formed through EDM of RB-SiC [10]. Three regions of subsurface damage were also identified as a resolidified layer, heat-affected zone and microcrack region in EDM of 4H-SiC [19]. Furthermore, the material migration from the tool electrode to the workpiece surface resulted in the contamination of the machined surface [20]. This surface and subsurface damage is harmful to the integrity of the machined surface, which should be reversed through subsequent processes.

The EDDG process offers the possibility to reduce the damage induced by EDM through simultaneous diamond grinding. However, the surface and subsurface damage is influenced by the discharge energy. A high discharge energy leads to poor grinding 
This is a peer-reviewed, accepted author manuscript of the following research article: Rao, X., Zhang, F.,

Lu, Y., Luo, X., \& Chen, F. (Accepted/In press). Surface and subsurface damage of reactionbonded silicon carbide induced by electrical discharge diamond grinding. International Journal of Machine Tools and Manufacture. https://doi.org/10.1016/j.ijmachtools.2020.103564

performance of the diamond wheel because of the premature pullout of grits [9]. The deeper discharge craters generated at high voltage are not completely removed by grinding [21]. The main damage types in the pure grinding process, such as pulverization and microcracks $[22,23]$, change owing to the discharge-induced thermal softening. Therefore, understanding the effects of EDM and diamond grinding on the surface and subsurface damage is essential for quality control in EDDG of RB-SiC. However, limited literature can be found regarding the surface and subsurface damage induced by the interaction between EDM and diamond grinding during EDDG.

This study focused on the analysis of the surface and subsurface damage in EDDG of RB-SiC. The effects of EDM and diamond grinding on the surface and subsurface damage were investigated at three different discharge-energy levels. The grinding tracks and phase transformation on the ground surface were characterized via scanning electron microscopy (SEM) and Raman spectroscopy, respectively. Transmission electron microscopy (TEM) was conducted to examine the microstructure and detect the subsurface damage. According to the fast Fourier transformation (FFT) patterns of the phases on the subsurface, the nanostructure changes at different locations under the interactions between EDM and diamond grinding were determined.

\section{Experimental procedures}

\subsection{Material}

Commercial RB-SiC provided by Goodfellow Cambridge Ltd. (UK) was used in the experiments. To facilitate the subsequent detection and characterization, the received 
This is a peer-reviewed, accepted author manuscript of the following research article: Rao, X., Zhang, F., Lu, Y., Luo, X., \& Chen, F. (Accepted/In press). Surface and subsurface damage of reactionbonded silicon carbide induced by electrical discharge diamond grinding. International Journal of Machine Tools and Manufacture. https://doi.org/10.1016/j.ijmachtools.2020.103564

RB-SiC was cut into small blocks with dimensions of $10 \mathrm{~mm} \times 10 \mathrm{~mm} \times 6 \mathrm{~mm}$ using wire EDM. The as-received $\mathrm{RB}-\mathrm{SiC}$ contained approximately 10 vol.\% free $\mathrm{Si}$. Additionally, a pristine RB-SiC sample was polished with a diamond slurry having a particle size of $0.25 \mu \mathrm{m}$ until a surface finish of $20 \mathrm{~nm}$ (Sa) was obtained, which was used to determine the subsurface damage in the EDDG process through comparison. In a previous study [24], X-ray diffraction analysis revealed that an RB-SiC sample primarily consisted of $6 \mathrm{H}-\mathrm{SiC}$ phases. The main properties of the $\mathrm{RB}-\mathrm{SiC}$ supplied by Goodfellow Cambridge Ltd. are listed in Table 1.

Table 1 Properties of the RB-SiC

\begin{tabular}{ll}
\hline Property & Value \\
\hline Density $\left(\mathrm{g} / \mathrm{cm}^{3}\right)$ & 3.10 \\
Tensile modulus $(\mathrm{GPa})$ & 410 \\
Vickers hardness $\left(\mathrm{kgf} / \mathrm{mm}^{2}\right)$ & $2500-3500$ \\
Fracture toughness $\left(\mathrm{MPa} \cdot \mathrm{m}^{1 / 2}\right)$ & 4.0 \\
Electrical resistivity $(\Omega \cdot \mathrm{cm})$ & $10^{2}-10^{3}$ \\
Thermal conductivity $[\mathrm{W} /(\mathrm{m} \cdot \mathrm{K})]$ & $150-200$ \\
Coefficient of thermal expansion $\left(\times 10 \mathrm{~K}^{-1}\right)$ & $4.3-4.6$ \\
Specific heat $[\mathrm{J} /(\mathrm{K} \cdot \mathrm{kg})]$ & 1100 \\
Melting point $(\mathrm{K})$ & 3000 \\
Free Si content $(\mathrm{vol} . \%)$ & 10 \\
\hline
\end{tabular}


This is a peer-reviewed, accepted author manuscript of the following research article: Rao, X., Zhang, F.,

Lu, Y., Luo, X., \& Chen, F. (Accepted/In press). Surface and subsurface damage of reactionbonded silicon carbide induced by electrical discharge diamond grinding. International Journal of Machine Tools and Manufacture. https://doi.org/10.1016/j.ijmachtools.2020.103564

\subsection{Experimental setup}

The experiments were conducted using a precision grinder with a horizontal spindle (FS420LC, Germany), as shown in Fig. 1. The RB-SiC sample was fixed by a bench vise, which was mounted on an insulating plate. The insulating plate was fastened on a steel plate, and then the steel plate was fixed on the electromagnetic worktable. An ironbonded diamond grinding wheel was used to machine the RB-SiC sample. A pulse power supply (HDMD-V) with three open-circuit voltage adjustments of 70, 100, and $140 \mathrm{~V}$ was employed to provide the required discharge energy during the process. The open-circuit voltages and on-time/off-time of the electrical discharge pulse were changed by adjusting the knobs on the operation panel. A mixed liquid comprising 6.7 vol.\% emulsified oil and 93.3 vol.\% distilled water was used as the grinding/dielectric fluid.

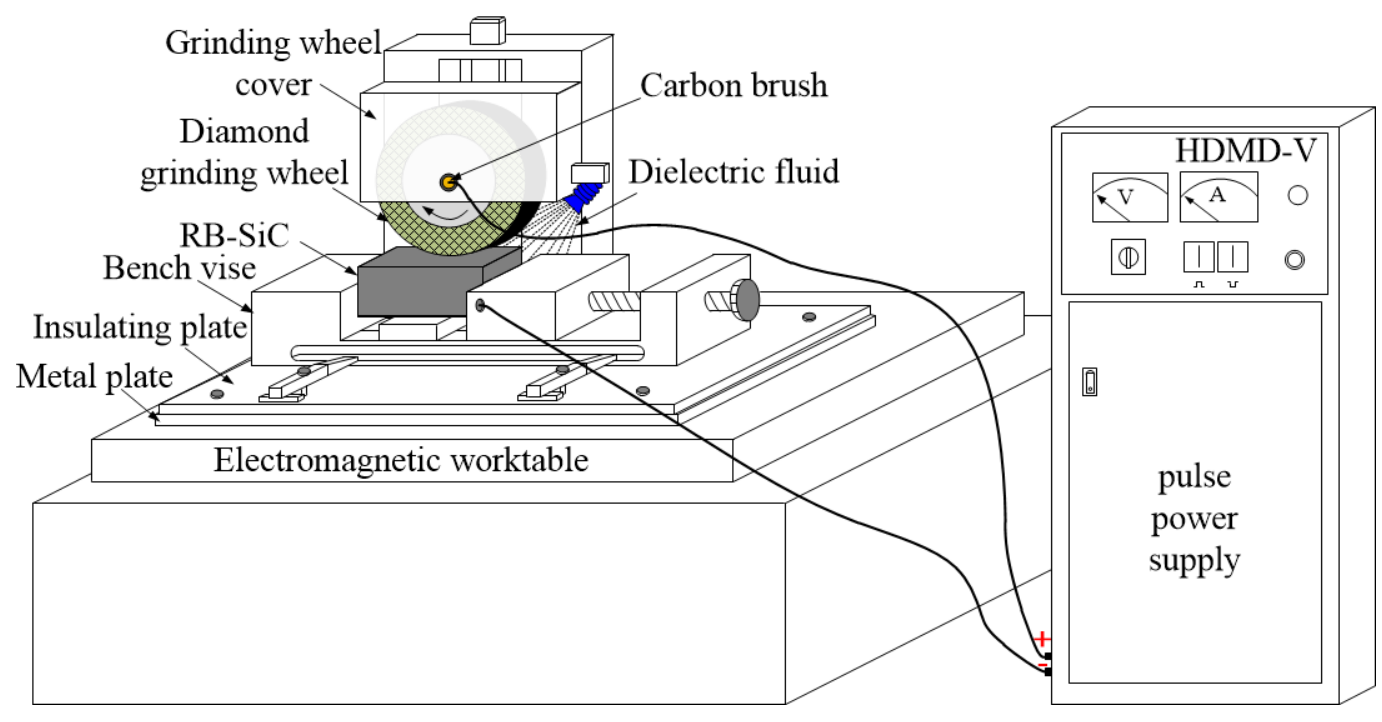

Fig. 1 Schematic of the experimental setup.

During EDDG of the RB-SiC, the iron-bonded diamond grinding wheel was connected to the positive pole of the power supply by a carbon brush fastened on the cover, 
This is a peer-reviewed, accepted author manuscript of the following research article: Rao, X., Zhang, F., Lu, Y., Luo, X., \& Chen, F. (Accepted/In press). Surface and subsurface damage of reactionbonded silicon carbide induced by electrical discharge diamond grinding. International Journal of Machine Tools and Manufacture. https://doi.org/10.1016/j.ijmachtools.2020.103564

whereas the RB-SiC sample was connected to the negative pole of the power supply by the bench vise. As previously reported [6], the RB-SiC material was removed by both EDM and diamond grinding in the EDDG process. The EDDG conditions are listed in Table 2. To investigate the effects of the discharge energy on the surface and subsurface damage, three discharge-energy levels, defined as lowest discharge energy, middle discharge energy, and highest discharge energy, were applied to the RB-SiC samples by changing the open-circuit voltage and on-time of the electrical discharge pulse, as listed in Table 2.

Table 2 EDDG conditions

\begin{tabular}{|c|c|}
\hline Parameter & Value \\
\hline \multirow{3}{*}{ Diamond wheel } & $\# 120$ (grain size of $106-125 \mu \mathrm{m}$ ), $100 \%$ concentration, \\
\hline & \\
\hline & iron-bonded, diameter of $D=200 \mathrm{~mm}$, width of $B=15 \mathrm{~mm}$ \\
\hline Spindle speed (r/min) & 2880 \\
\hline Feed rate $(\mathrm{mm} / \mathrm{s})$ & 27.5 \\
\hline Grinding depth $(\mu \mathrm{m})$ & 10 \\
\hline \multirow[t]{3}{*}{ Polarity } & Grinding wheel (+), RB-SiC sample (-) \\
\hline & Lowest discharge energy: \\
\hline & Voltage $U=70 \mathrm{~V}$, Pulse $_{o n}=10 \mu \mathrm{s}$, Pulse $_{o f f}=50 \mu \mathrm{s}$ \\
\hline \multirow[t]{3}{*}{ Discharge conditions } & Middle discharge energy: \\
\hline & Voltage $U=100 \mathrm{~V}$, Pulse $_{o n}=50 \mu \mathrm{s}$, Pulse $_{o f f}=50 \mu \mathrm{s}$ \\
\hline & Highest discharge energy: \\
\hline
\end{tabular}


This is a peer-reviewed, accepted author manuscript of the following research article: Rao, X., Zhang, F., Lu, Y., Luo, X., \& Chen, F. (Accepted/In press). Surface and subsurface damage of reactionbonded silicon carbide induced by electrical discharge diamond grinding. International Journal of Machine Tools and Manufacture. https://doi.org/10.1016/j.ijmachtools.2020.103564

Voltage $U=140 \mathrm{~V}$, Pulse $_{o n}=90 \mu \mathrm{s}$, Pulse $_{o f f}=50 \mu \mathrm{s}$

\subsection{Specimen preparation for TEM detection}

After the EDDG process, to investigate the subsurface damage at different dischargeenergy levels, a TEM specimen was prepared. In a previous study [5], the machined surface of an RB-SiC sample subjected to EDDG was characterized by an EDM zone and a grinding zone. A cross-sectional TEM specimen was prepared with a boundary between the two zones to investigate the effects of EDM and diamond grinding on the subsurface damage, as shown in Fig. 2 (a). First, the cross-sectional specimen perpendicular to the grinding direction was machined via a focused ion beam (FIB) using a FEI Scios DualBeam microscope (Electron Microscopy Center, Shenzhen University), which had a gallium ion source. Then, it was lifted out using an in situ micromanipulator and attached to a specimen holder, as shown in Fig. 2 (b). Subsequently, the specimen was thinned by the FIB in situ until a thickness of $<100 \mathrm{~nm}$ was obtained. 
This is a peer-reviewed, accepted author manuscript of the following research article: Rao, X., Zhang, F., Lu, Y., Luo, X., \& Chen, F. (Accepted/In press). Surface and subsurface damage of reactionbonded silicon carbide induced by electrical discharge diamond grinding. International Journal of Machine Tools and Manufacture. https://doi.org/10.1016/j.ijmachtools.2020.103564

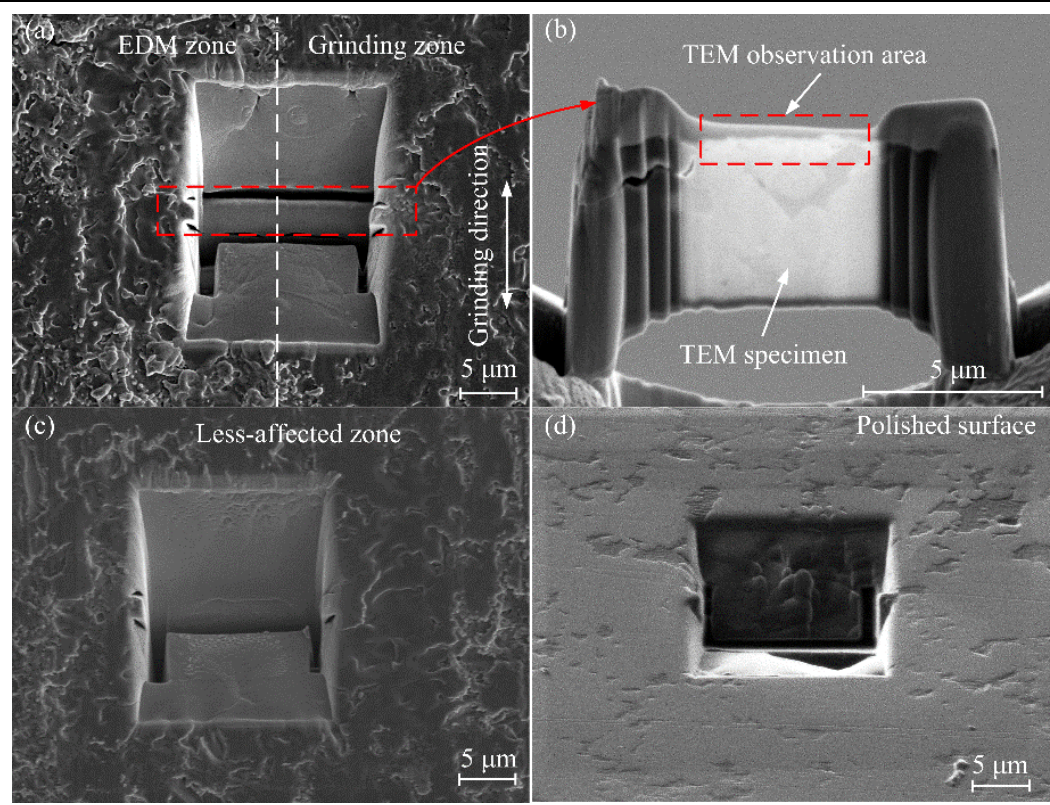

Fig. 2 TEM specimen preparation. (a) Location of the cross-sectional specimen machined by FIB, (b) FIB-thinned TEM specimen, (c) the less-thermally affected zone for TEM specimen preparation, and (d) the polished pristine RB-SiC for TEM specimen preparation.

As shown in Fig. 2 (c), a region far from the EDM zone on the surface of the sample machined at middle discharge energy was selected to prepare the TEM specimen to investigate the interaction between EDM and diamond grinding on subsurface damage. This region is referred to as the "less-thermally affected zone" hereinafter. Additionally, a TEM specimen was prepared on the polished surface of the pristine RB-SiC sample mentioned in Section 2.1 for comparison, as shown in Fig. 2 (d). All the TEM specimens were coated with platinum before the FIB operation to prevent thermal damage induced by the FIB.

\subsection{Surface and subsurface characterization}

The surface topography of the machined RB-SiC sample was observed via SEM 
This is a peer-reviewed, accepted author manuscript of the following research article: Rao, X., Zhang, F.,

Lu, Y., Luo, X., \& Chen, F. (Accepted/In press). Surface and subsurface damage of reactionbonded silicon carbide induced by electrical discharge diamond grinding. International Journal of Machine Tools and Manufacture. https://doi.org/10.1016/j.ijmachtools.2020.103564

(Merlin Compact). The surface roughness was measured by a white light interferometer (Zygo cp-200) at ten different locations, and then the average was taken as the roughness results. To identify the possible phase transformation on the ground surface, laser micro-Raman spectroscopy was conducted across the EDM and grinding zones using an inVia Reflex Raman system (Renishaw, UK). For all the machined RB-SiC specimens, an excitation source with a $532 \mathrm{~nm}$ wavelength and a laser power of $50 \mathrm{~mW}$ was used. TEM (FEI Talos F200x, FEI Co., USA) was used to examine the subsurface structure of the specimens at an acceleration voltage of $200 \mathrm{kV}$. Additionally, high angle annular dark field scanning TEM (STEM) images and energy dispersive X-ray spectroscopy (EDS, EDAX, USA) were performed to analyze the elemental compositions on the cross section of the TEM specimens. To improve the reliability of the result, three repeated detections were conducted during at least 20 min each time that the cross section was detected by EDS.

\section{Theoretical analysis of surface and subsurface damage in EDDG process}

The surface and subsurface damage in EDDG is very complex because of the interactions between EDM and diamond grinding. Therefore, to simplify the analysis of the surface and subsurface damages, some assumptions are made.

a) Discharge sparks occur at the front of diamond grinding on the unmachined surface.

b) The crater size is a function of the discharge energy transferred to the workpiece.

c) The crater is considered as a part of a sphere whose center is on the middle line of the gap between the iron bond of the grinding wheel and the unmachined surface. 
This is a peer-reviewed, accepted author manuscript of the following research article: Rao, X., Zhang, F., Lu, Y., Luo, X., \& Chen, F. (Accepted/In press). Surface and subsurface damage of reactionbonded silicon carbide induced by electrical discharge diamond grinding. International Journal of Machine Tools and Manufacture. https://doi.org/10.1016/j.ijmachtools.2020.103564

d) The heights of diamond grits protruding out of the grinding wheel are identical.

\subsection{Surface and subsurface damage induced by EDM}

Based on above assumptions, a relationship between cutting depth of diamond grit and diameter of crater is shown in Fig.3. The crater volume $V_{c}$ can be calculated as

$$
V_{c}=\pi\left(\frac{d_{c}^{2} h}{8}+\frac{h^{3}}{6}\right)
$$

where $d_{c}$ and $h$ are the diameter and depth of the crater, respectively. According to the assumption (c), the spherical center (the point " $O$ " in Fig. 3) of the crater is in the middle of the gap. Therefore, $d_{c}$ and $h$ have a relationship given by

$$
d_{c}=2 \sqrt{h^{2}+h l}
$$

where $l$ is the gap distance between the iron bond of the grinding wheel and the unmachined surface.

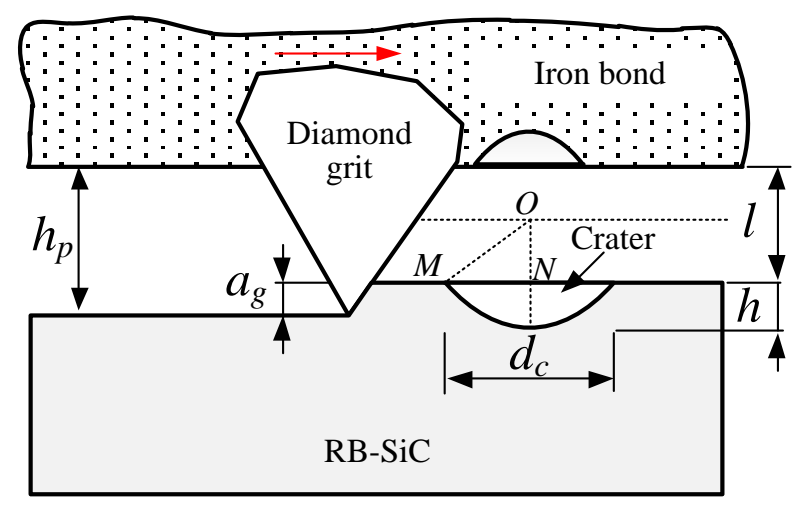

Fig.3 Relationship between cutting depth of diamond grit and diameter of crater.

In the EDDG process, the gap between the iron bond and unmachined surface is governed by protrusion height $\left(h_{p}\right)$ and cutting depth $\left(a_{g}\right)$ of the diamond grit. Then, the gap distance can be expressed by $h_{p}$ and $a_{g}$.

$$
l=h_{p}-a_{g}
$$


This is a peer-reviewed, accepted author manuscript of the following research article: Rao, X., Zhang, F.,

Lu, Y., Luo, X., \& Chen, F. (Accepted/In press). Surface and subsurface damage of reactionbonded silicon carbide induced by electrical discharge diamond grinding. International Journal of Machine Tools and Manufacture. https://doi.org/10.1016/j.ijmachtools.2020.103564

The crater is formed due to the melting and vaporization of material induced by the discharge energy. However, the discharge energy is transferred to the material at a ratio of $\eta$ according to $[25,26]$. If the discharge energy transferred to the material is utilized for formation of the crater, the relationship between crater and discharge energy can be expressed by a proportionality constant $K^{\prime}$,

$$
V_{c}=K^{\prime}\left(\eta E_{Q}\right)
$$

where $E_{Q}$ is the discharge energy induced by a single discharge spark, which can be given by

$$
E_{Q}=U I \tau
$$

where $U$ is the discharge/breakdown voltage, $I$ is the mean peak current, and $\tau$ is the pulse-on time. In a closed circuit, the current and voltage commonly have the following relationship:

$$
U=I \cdot R_{C}
$$

where $R_{c}$ is the resistance of the closed circuit, which can be considered as a constant. Therefore, the depth of the crater can be expressed by a combination of Eqs. (1)-(6).

$$
\begin{aligned}
& h=\frac{1}{12 R_{c}}\left(K U^{2} \tau-R_{c}\left(h_{p}-a_{g}\right)^{3}+108 U \sqrt{144 K^{2} U^{2} \tau^{2}-6 K R_{c}\left(h_{p}-a_{g}\right)^{3} \tau}\right)^{1 / 3}- \\
& \frac{3 R_{c}\left(h_{p}-a_{g}\right)^{2}}{4\left(6 K U^{2} \tau-R_{c}\left(h_{p}-a_{g}\right)^{3}-108 U \sqrt{144 K^{2} U^{2} \tau^{2}-6 K R_{c}\left(h_{p}-a_{g}\right)^{3} \tau}\right)^{1 / 3}}-\frac{h_{p}-a_{g}}{4}
\end{aligned}
$$

Eq. (7) indicates that the depth of the crater size increases with the increase in discharge voltage and pulse-on time, whereas it decreases with the increase in protrusion height of the diamond grit. Therefore, the influence of discharge voltage and pulse-on time on 
This is a peer-reviewed, accepted author manuscript of the following research article: Rao, X., Zhang, F.,

Lu, Y., Luo, X., \& Chen, F. (Accepted/In press). Surface and subsurface damage of reactionbonded silicon carbide induced by electrical discharge diamond grinding. International Journal of Machine Tools and Manufacture. https://doi.org/10.1016/j.ijmachtools.2020.103564

the damage induced by EDM were discussed in present work, as summarized in Table

2. However, the cutting depth $\left(a_{g}\right)$ of the diamond grit depends on the grinding process.

\subsection{Surface and subsurface damage induced by diamond grinding}

In the grinding process, the cutting depth of the diamond grit is variable, as depicted in

Fig. 4. $a_{g}$ gradually increases from zero to the maximum value during the grinding process. The maximum cutting depth $\left(a_{g m}\right)$, i.e., the undeformed chip thickness, can be calculated as follows $[27,28]$ :

$$
a_{g m}=\left(\frac{3}{\chi \tan \theta}\right)^{1 / 2}\left(\frac{v_{w}}{v_{s}}\right)^{1 / 2}\left(\frac{a_{p}}{d_{s}}\right)^{1 / 4}
$$

where $v_{s}$ and $v_{w}$ are the line speed of the grinding wheel and feed rate, respectively. $a_{p}$ and $d_{s}$ are the grinding depth and diameter of the grinding wheel, respectively. $\theta$ is the half-inclined angle of the diamond grits, which was set as $74^{\circ}$ in the study. $\chi$ is the active grain density of the grinding wheel, which is determined by the structural parameters of the grinding wheel [28],

$$
\chi=\frac{4 f}{d_{g}^{2}\left(\frac{4 \pi}{3 V_{g}}\right)^{2 / 3}}
$$

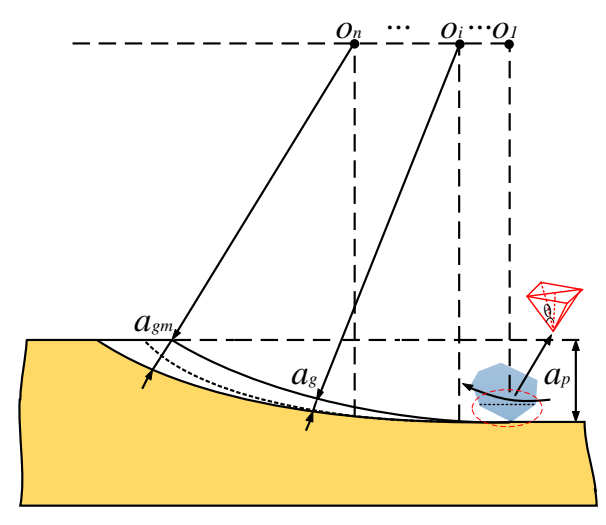

Fig. 4 Cutting depth for one diamond grit in the grinding process.

where $f$ is the fraction of the active grits (taken as 0.3 [28]), and $d_{g}$ is the average size 
This is a peer-reviewed, accepted author manuscript of the following research article: Rao, X., Zhang, F.,

Lu, Y., Luo, X., \& Chen, F. (Accepted/In press). Surface and subsurface damage of reactionbonded silicon carbide induced by electrical discharge diamond grinding. International Journal of Machine Tools and Manufacture. https://doi.org/10.1016/j.ijmachtools.2020.103564

of the grits. $V_{g}$ is the volume fraction of the diamond grits, which is 0.25 when the grinding wheel has a diamond-grit concentration of $100 \%$. Therefore, the undeformed chip thickness was calculated as $0.58-0.69 \mu \mathrm{m}$ according to the parameters in Table 2 . However, in grinding of ceramic materials, there is a critical depth related to material removal in the brittle and ductile regimes. The critical depth of the ductile-brittle transition $\left(h_{c}\right)$ was proposed by Bifano et al. [29] for a series of ceramic materials, including $\mathrm{SiC}$, and was expressed as a function of the material properties.

$$
h_{c}=0.15\left(\frac{E}{H}\right)\left(\frac{K_{c}}{H}\right)^{2}
$$

where $E, H$, and $K_{c}$ are the elastic modulus, Vickers hardness, and fracture toughness of the material, respectively. According to the material properties in Table 1, the critical depth of RB-SiC was in the range of $23-63.0 \mathrm{~nm}$, which was lower than that of $a_{g m}$. The results supported the experimental findings that damages such as cracks and fractures were generated in the subsurface.

\subsection{Surface and subsurface damage induced by the interactions}

In the EDDG process, EDM also caused dressing of the grinding wheel. As a result, the active grits increased during the grinding process. The crater depth was then decreased because of the reduction in $a_{g m}$ according to Eqs. (7)-(9). However, if the grinding wheel had excessive dressing at the highest discharge energy, a deeper crater was formed.

The discharge energy transferred to the workpiece changes the material properties of $\mathrm{RB}-\mathrm{SiC}$ in the grinding zone, affecting the critical depth $h_{c}$. In a previous study [24], 
This is a peer-reviewed, accepted author manuscript of the following research article: Rao, X., Zhang, F.,

Lu, Y., Luo, X., \& Chen, F. (Accepted/In press). Surface and subsurface damage of reactionbonded silicon carbide induced by electrical discharge diamond grinding. International Journal of Machine Tools and Manufacture. https://doi.org/10.1016/j.ijmachtools.2020.103564

the critical depth $h_{c}$ was modified according to the temperature-dependent material properties. It was given as

$$
h_{c}(T)=\left(0.52+0.85 \exp \left(-T / T_{0}\right)\right)\left(\frac{E(T)}{H(T)}\right)\left(\frac{K_{c}(T)}{H(T)}\right)^{2}
$$

where $E(T), H(T)$ and $K_{c}(T)$ are the temperature-dependent elastic modulus, Vickers hardness, and fracture toughness of the material, respectively. The critical depth reported increased to $0.39 \mu \mathrm{m}$ when scratching the RB-SiC specimen at an elevated temperature [24], which is close to the $a_{g m}$ value calculated in Section 3.2. This indicates that the ductile grinding performance of diamond grits can be improved by incorporating EDM into the EDDG process. The subsurface damage induced by diamond grinding, such as cracks and fractures, is then reduced with an increase in the discharge energy.

\section{Characterization of surface damage}

\subsection{Surface topography}

Fig. 5 shows the typical machined surface of the RB-SiC ceramics ground by EDDG. Two distinct zones, i.e., EDM and grinding zones, with different surface characteristics were identified, as shown in Fig. 5 (a). In the grinding zone, a relatively flat surface was obtained, because the diamond grinding dominated the material removal of the RBSiC sample. The discharge-induced thermal energy caused material softening, resulting in large ductile grinding tracks at the boundary between the EDM and the grinding zones, as shown in Fig. 5 (b). Craters were formed in the EDM zone. The RB-SiC material melted by discharge sparks was rapidly cooled by the dielectric fluid, resulting 
This is a peer-reviewed, accepted author manuscript of the following research article: Rao, X., Zhang, F., Lu, Y., Luo, X., \& Chen, F. (Accepted/In press). Surface and subsurface damage of reactionbonded silicon carbide induced by electrical discharge diamond grinding. International Journal of Machine Tools and Manufacture. https://doi.org/10.1016/j.ijmachtools.2020.103564

in the formation of resolidified material in the EDM zone, as shown in Fig. 5 (c). The different surface topographies reveal the dominant material removal mechanism in the EDM and grinding zones, respectively.

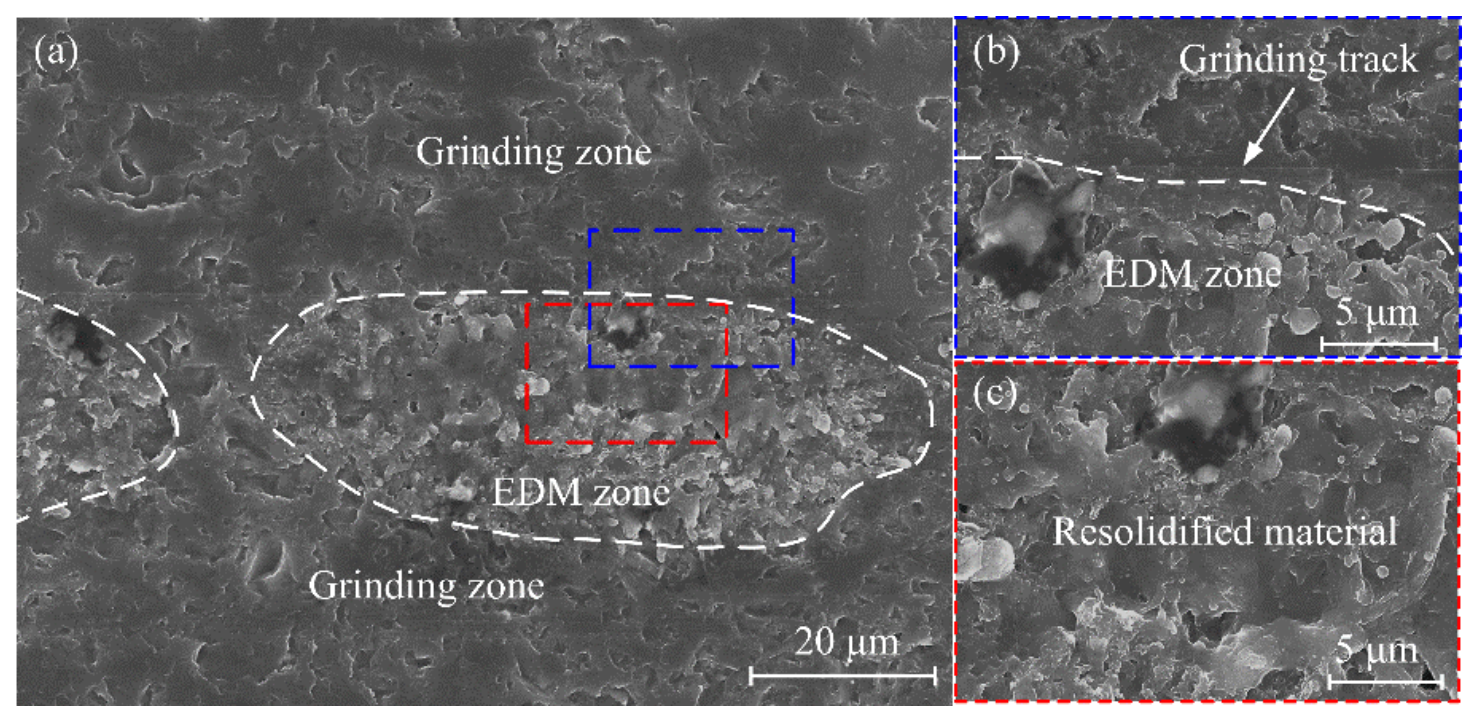

Fig. 5 (a) Typical machined surface of the RB-SiC specimen ground by EDDG. (b)

Boundary between the grinding and EDM zones. (c) EDM zone.

However, Eq. (7) indicates that the surface damage induced by EDM increases with the discharge energy. Fig. 6 presents the definitions and measurement results of the width $(B)$ and length $(L)$ of the EDM zone. The averages of 10 measurement data and their standard deviations at different discharge-energy levels are shown in Fig. 6 (b). Both the width and length of the EDM zone increased with the increase in discharge energy. It indicated that the RB-SiC removed by EDM increased at high discharge energy. As a result, the surface damage, such as craters, induced by EDM also increased with the discharge energy. The results verified the model of surface damage induced by EDM. 
This is a peer-reviewed, accepted author manuscript of the following research article: Rao, X., Zhang, F.,

Lu, Y., Luo, X., \& Chen, F. (Accepted/In press). Surface and subsurface damage of reactionbonded silicon carbide induced by electrical discharge diamond grinding. International Journal of Machine Tools and Manufacture. https://doi.org/10.1016/j.ijmachtools.2020.103564

(a)

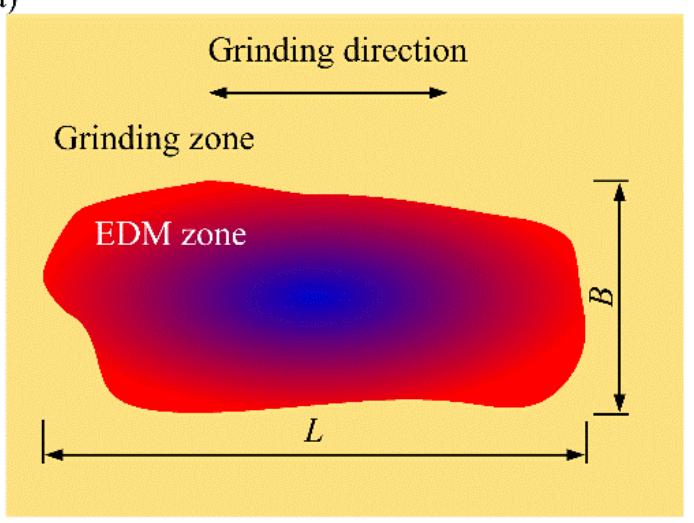

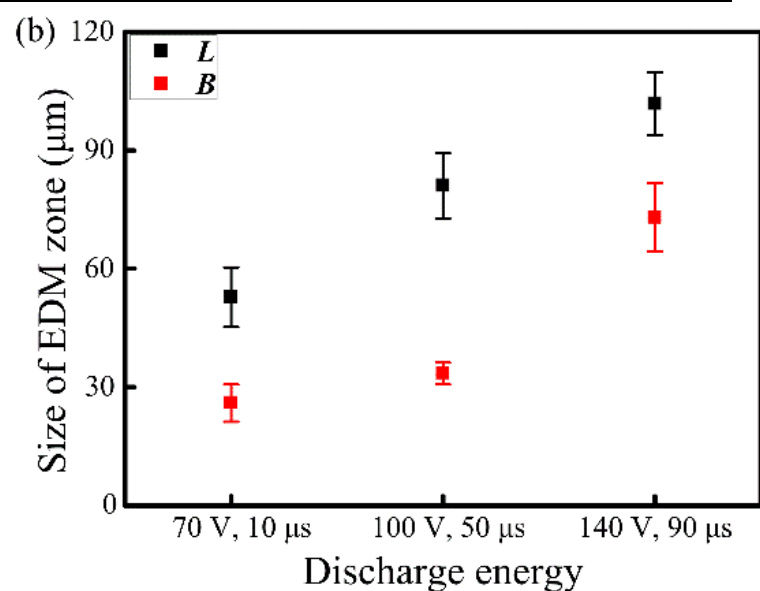

Fig. 6 Sizes of the EDM zone at different discharge-energy levels. (a) Size definition and (b) measurement results.

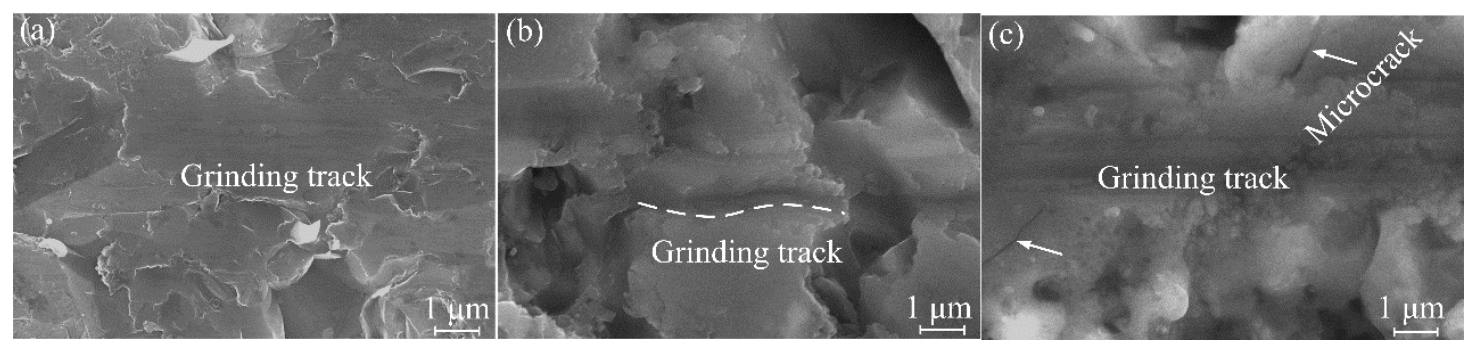

Fig. 7 Micromorphology of the grinding zone at different discharge-energy levels. (a) $U=70 \mathrm{~V}$, Pulse $_{o n}=10 \mu \mathrm{s}$, (b) $U=100 \mathrm{~V}$, Pulse $_{o n}=50 \mu \mathrm{s}$, and (c) $U=140 \mathrm{~V}$, Pulse $_{o n}=$ $90 \mu \mathrm{s}$.

The surface damage induced by diamond grinding are shown in Fig. 7. Owing to material softening induced by the thermal energy, plastic deformation of the bulk material occurred under the diamond grinding action. Although the dominant type of surface damage was fracture, ductile grinding tracks were visible at the three dischargeenergy levels. Fig. 7 (a) shows shallower grinding tracks with a flat surface at the lowest discharge energy, whereas curved grinding tracks were observed owing to more plastic deformation at the middle discharge energy, as shown in Fig. 7 (b). These results reveal 
This is a peer-reviewed, accepted author manuscript of the following research article: Rao, X., Zhang, F.,

Lu, Y., Luo, X., \& Chen, F. (Accepted/In press). Surface and subsurface damage of reactionbonded silicon carbide induced by electrical discharge diamond grinding. International Journal of Machine Tools and Manufacture. https://doi.org/10.1016/j.ijmachtools.2020.103564

that the incorporation of EDM into the EDDG process enhanced the ductile grinding performance of the diamond grits and reduced the fracture damage. However, at the highest discharge energy, the grinding tracks were covered with oxidized debris, as shown in Fig. 7 (c). Microcracks were generated owing to the excessive thermal stress induced by the discharge energy. This implies that the excessive discharge energy led to a new type of surface damage, even though ductile material removal was promoted. The 3D surface morphology and surface roughness measured by white light interferometer are shown in Fig. 8. The machined surface roughness initially decreases and then increases with increase of discharge energy.
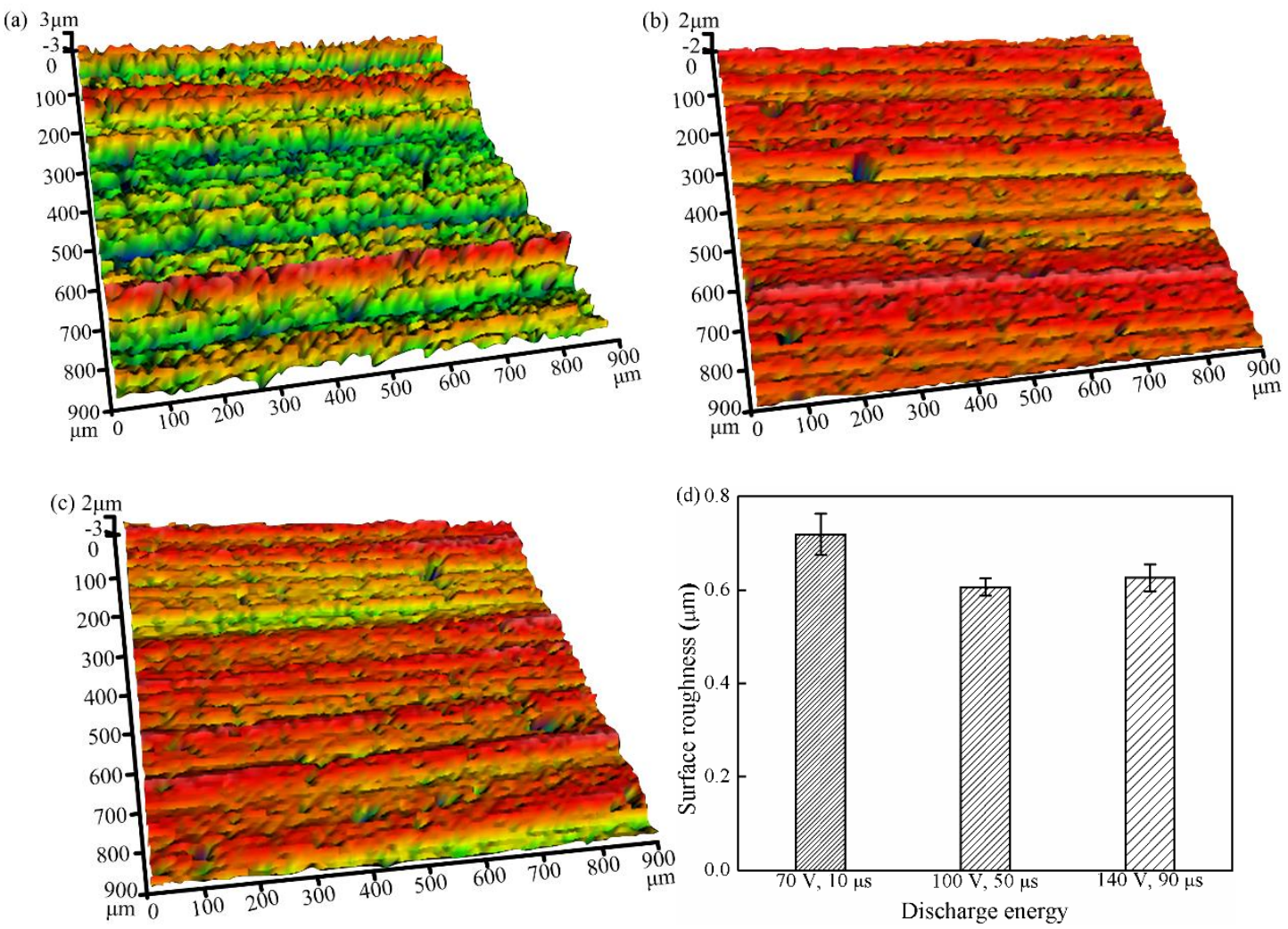

Fig. 8 3D surface morphology at different discharge-energy levels: (a) $U=70 \mathrm{~V}$, Pulse on $=10 \mu \mathrm{s}$, (b) $U=100 \mathrm{~V}$, Pulse $_{o n}=50 \mu \mathrm{s}$, and (c) $U=140 \mathrm{~V}$, Pulse $e_{o n}=90 \mu \mathrm{s}$, and (d) 
This is a peer-reviewed, accepted author manuscript of the following research article: Rao, X., Zhang, F., Lu, Y., Luo, X., \& Chen, F. (Accepted/In press). Surface and subsurface damage of reactionbonded silicon carbide induced by electrical discharge diamond grinding. International Journal of Machine Tools and Manufacture. https://doi.org/10.1016/j.ijmachtools.2020.103564

surface roughness.

\subsection{Phase transformation}

An area involving both the EDM and grinding zones was detected to investigate the possible phase transformation using Raman spectroscopy. Fig. 9 shows the phase distribution of the tested area at the middle discharge energy. The SiC and Si phases were mainly distributed in the grinding zone and at the boundary between the EDM and grinding zones. The $\mathrm{C}$ phase was abundant in the EDM zone, as shown in Fig. 9 (c). It indicated the decomposition of $\mathrm{SiC}$ induced by EDM. Because of the low melting and evaporation points (1410 and $3200{ }^{\circ} \mathrm{C}[10]$, respectively) of the Si phase, it was melted and evaporated. Moreover, the Si phase had a higher electrical conductivity than the $\mathrm{SiC}$ grains [20], which also contributed to the preferential melting and evaporation of the $\mathrm{Si}$ phase. Therefore, only $\mathrm{C}$ produced by the decomposition of $\mathrm{SiC}$ remained at the center of the EDM zone. However, the Si shown in Fig. 9 (d) was likely the remaining $\mathrm{Si}$ in the $\mathrm{RB}-\mathrm{SiC}$ rather than a product of the decomposition of the $\mathrm{SiC}$ phase.

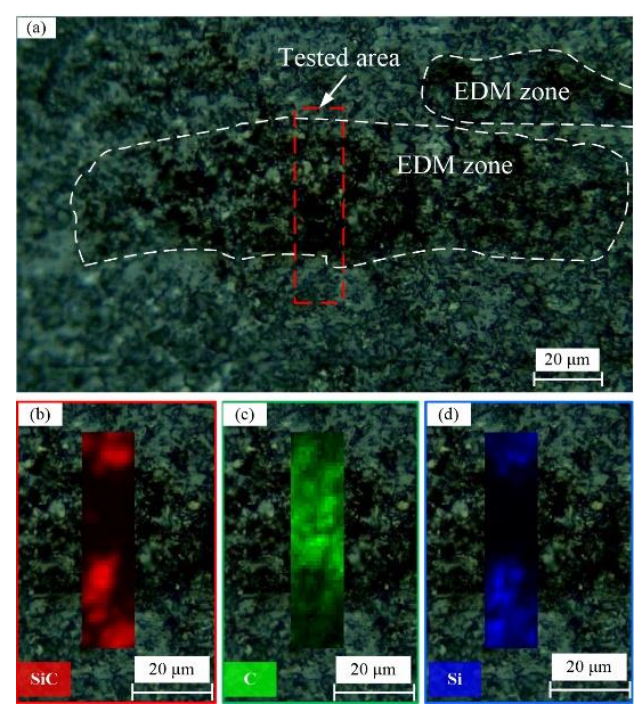

Fig. 9 (a) Illustration of the tested area detected by Raman spectroscopy and (c) - (d) 
This is a peer-reviewed, accepted author manuscript of the following research article: Rao, X., Zhang, F.,

Lu, Y., Luo, X., \& Chen, F. (Accepted/In press). Surface and subsurface damage of reactionbonded silicon carbide induced by electrical discharge diamond grinding. International Journal of Machine Tools and Manufacture. https://doi.org/10.1016/j.ijmachtools.2020.103564

distributions of phase in the tested area: (b) SiC phase, (c) C phase, and (d) Si phase.

To further investigate the interactions between EDM and diamond grinding on phase transformation, the $\mathrm{Si}, \mathrm{SiC}$, and $\mathrm{C}$ phases were examined by Raman spectroscopy in the grinding zone, at the boundary, and in the EDM zone, respectively. The effects of discharge energy were also considered, as shown in Fig. 10. The Si spectra influenced by discharge energy at different locations are presented in Fig. 10 (a1)-(a3). It is obvious that the spectrum of the Si phase shifted to low frequency with both high discharge energy and a location close to the EDM zone, indicating a variation in residual stress. The Raman shift relative to the standard Raman spectrum of Si at $520 \mathrm{~cm}^{-1}$ can be used to determine the residual stress, which is given as in $[30,31]$

$$
\sigma=-435 \Delta w
$$

where $\sigma(M P a)$ is the residual stress, and $\Delta w$ is the strain-induced shift of the Raman frequency. Eq. (12) indicates that compressive stress (approximately $1 \mathrm{GPa}$ ) existed in the pristine RB-SiC. The compressive stress was reduced by $174 \mathrm{MPa}$ in the grinding zone and at the boundary. However, the compressive stress was replaced by tensile stress in EDM zone, as shown in Fig. 10 (a3). It indicates that the discharge energy mainly induced tensile stress. Furthermore, the Si peak was broadened with the increase in discharge energy, particularly for the boundary (Fig. 10 (a2)). It indicates that nanocrystalline Si was generated and easily formed at the interaction between EDM and diamond grinding. Owing to the lack of sufficient grinding actions, an amorphous peak of Si at $464.1 \mathrm{~cm}^{-1}$ was observed at the highest discharge energy in the EDM zone. 
This is a peer-reviewed, accepted author manuscript of the following research article: Rao, X., Zhang, F.,

Lu, Y., Luo, X., \& Chen, F. (Accepted/In press). Surface and subsurface damage of reactionbonded silicon carbide induced by electrical discharge diamond grinding. International Journal of Machine Tools and Manufacture. https://doi.org/10.1016/j.ijmachtools.2020.103564
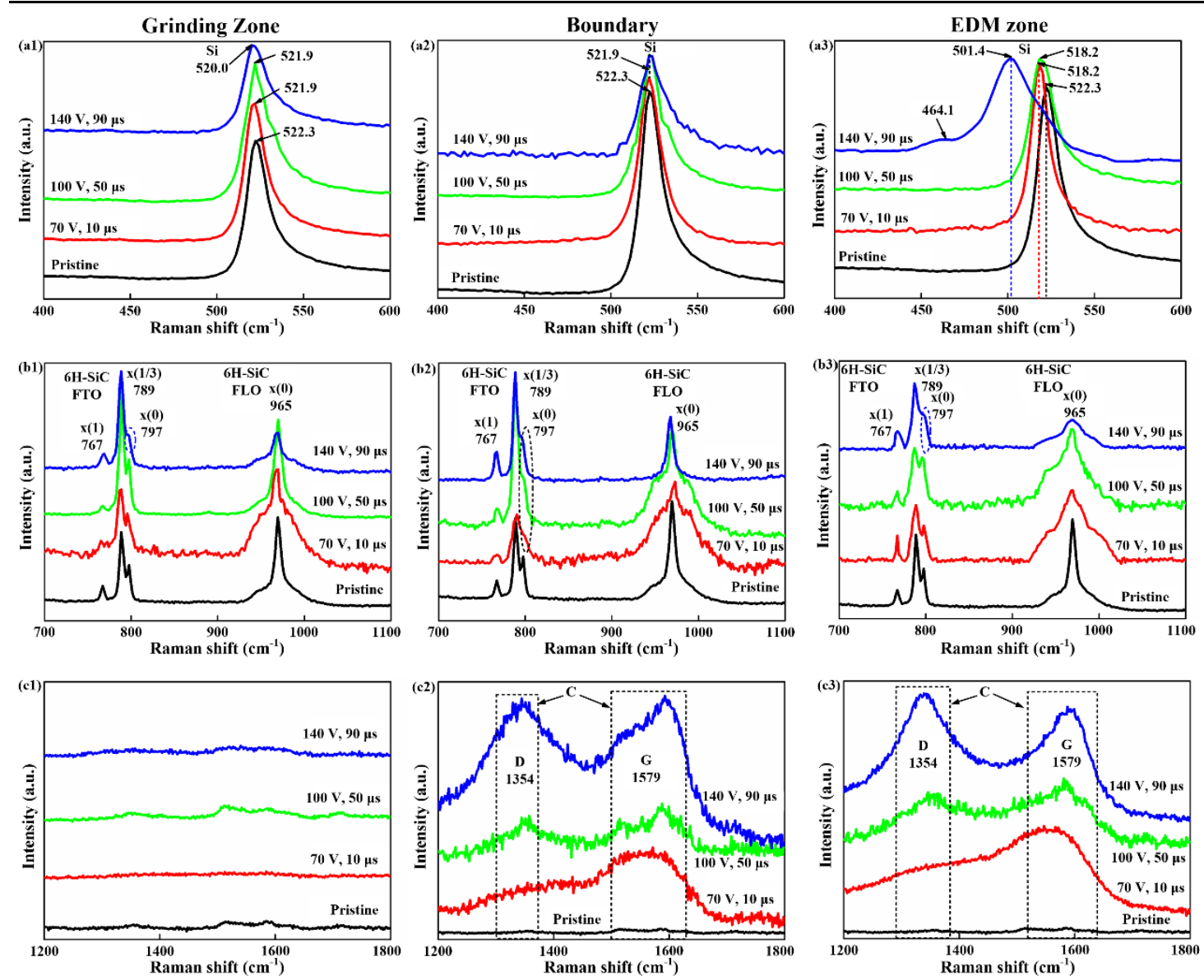

Fig.10 Raman spectra of Si, SiC, and C Phases influenced by discharge energy in the grinding zone, at the boundary, and in the EDM zone, respectively. (a1)-(a3) Raman spectra of Si, (b1)-(b3) Raman spectra of SiC, and (c1)-(c3) Raman spectra of C.

Fig. 10 (b1)-(b3) shows the SiC spectra influenced by discharge energy at different locations. Three continuous peaks at 767,789 and $797 \mathrm{~cm}^{-1}$ and a single peak at 965 $\mathrm{cm}^{-1}$ were observed, which were assigned to $6 \mathrm{H}-\mathrm{SiC}[32]$. In the grinding zone, the peaks of the folded modes of transverse optic (FTO) at 767, 789, and $797 \mathrm{~cm}^{-1}$ exhibited no difference from those of pristine $\mathrm{RB}-\mathrm{SiC}$ at low discharge energy. The spectrum of SiC exhibited no sharp peak at $797 \mathrm{~cm}^{-1}$ in Fig.10 (b1), indicating stacking faults generated at the highest discharge energy. This phenomenon also occurred in the EDM 
This is a peer-reviewed, accepted author manuscript of the following research article: Rao, X., Zhang, F.,

Lu, Y., Luo, X., \& Chen, F. (Accepted/In press). Surface and subsurface damage of reactionbonded silicon carbide induced by electrical discharge diamond grinding. International Journal of Machine Tools and Manufacture. https://doi.org/10.1016/j.ijmachtools.2020.103564

zone, as shown in Fig. 10 (b3). However, at the boundary, stacking faults were generated at all levels of discharge energy (Fig.10 (b2)). It indicates that the grinding action facilitated the stacking faults at low discharge energy. The peak of the folded mode of longitudinal optic (FLO) at $965 \mathrm{~cm}^{-1}$ was broadened with the increasing discharge energy and with a location close to the EDM zone, indicating the presence of nanocrystalline SiC. The intensity of the SiC peak, particularly for the FLO, decreased with the increasing discharge energy at the boundary and in the EDM zone, indicating a higher degree of $\mathrm{SiC}$ decomposition. The effects of discharge energy on $\mathrm{SiC}$ decomposition can be further confirmed by the spectra of $\mathrm{C}$ phase.

Fig. 10 (c1)-(c3) shows the Raman spectra in the range of $1200-1800 \mathrm{~cm}^{-1}$ influenced by discharge energy at different locations. Compared with the spectra for the grinding zone (Fig. 10 (c1)), extra Raman signature peaks at approximately $1354 \mathrm{~cm}^{-1}$ and 1579 $\mathrm{cm}^{-1}$ were identified as $\mathrm{D}$ and $\mathrm{G}$ peaks of the $\mathrm{C}$ phase at the boundary and in the EDM zone (Fig. 10 (c2) and (c3)). Because no $\mathrm{C}$ was generated in the grinding zone, the signature peaks reveal the decomposition of $\mathrm{SiC}$ caused by EDM. The intensities of these peaks (particularly the D peak) increased with the discharge energy. This suggests that $\mathrm{SiC}$ preferentially decomposed into $\mathrm{C}$ with disordered structures at a higher discharge energy given that the D peak indicates the presence of defects and disorder in the hexagonal $\mathrm{sp}^{2}$ carbon structure [19]. The nanostructure of the $\mathrm{C}$ component was examined via high-resolution TEM (HRTEM), as discussed in Section 5.3.

\section{Characterization of subsurface damage}


This is a peer-reviewed, accepted author manuscript of the following research article: Rao, X., Zhang, F., Lu, Y., Luo, X., \& Chen, F. (Accepted/In press). Surface and subsurface damage of reactionbonded silicon carbide induced by electrical discharge diamond grinding. International Journal of Machine Tools and Manufacture. https://doi.org/10.1016/j.ijmachtools.2020.103564

\subsection{Subsurface damage layer}

To determine the subsurface damage in the EDDG process, a cross section of pristine RB-SiC was firstly detected by TEM, as shown in Fig. 11 (a). It reveals stacking faults in the $\mathrm{SiC}$ grains, and dislocation in the $\mathrm{SiC}$ grain with phase boundary generated by the sintering process. However, the $\mathrm{SiC}$ grain below the polished surface was almost defect-free, except for a thin damage layer (about $68 \mathrm{~nm}$ ) induced by the polishing process. Moreover, no void was observed in the SiC grains. Thus, any subsurface damage beneath the machined surface must be induced by the EDDG process.
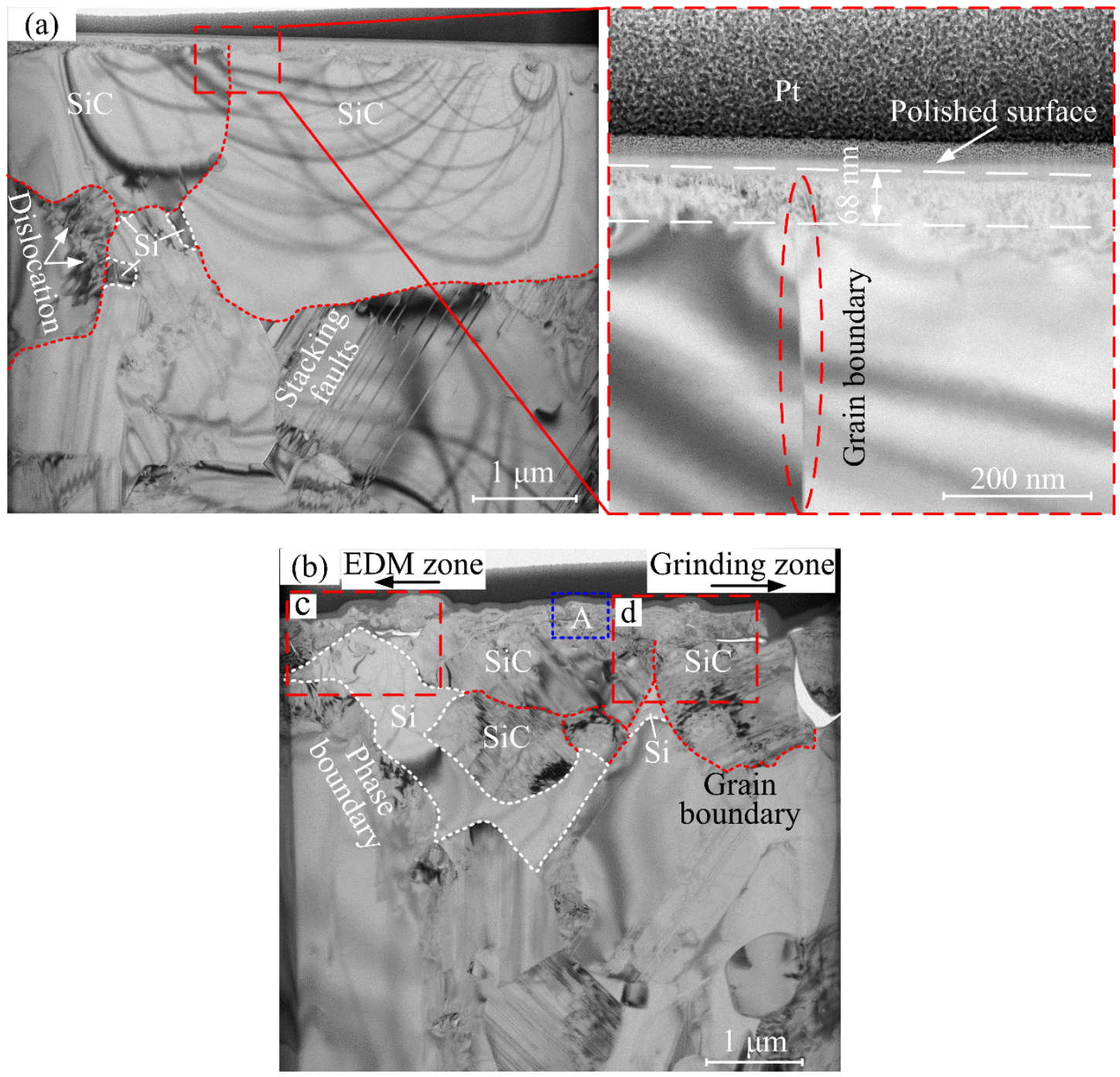
This is a peer-reviewed, accepted author manuscript of the following research article: Rao, X., Zhang, F.,

Lu, Y., Luo, X., \& Chen, F. (Accepted/In press). Surface and subsurface damage of reactionbonded silicon carbide induced by electrical discharge diamond grinding. International Journal of Machine Tools and Manufacture. https://doi.org/10.1016/j.ijmachtools.2020.103564
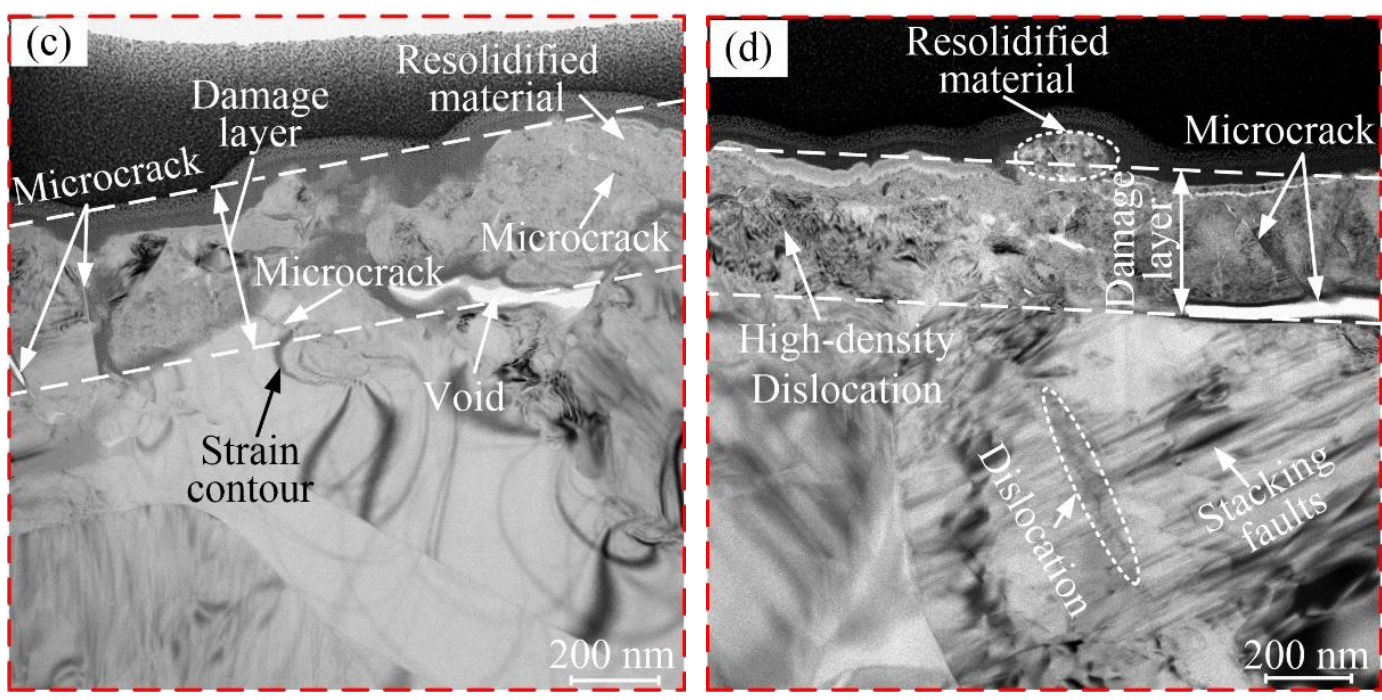

Fig. 11 Typical TEM images of subsurface damage. (a) Bright field (BF) image of pristine RB-SiC and (b) BF image of the cross section at middle energy. (c) and (d) enlarged images of the location close to EDM zone and grinding zone in (b), respectively.

Fig. 11 (b)-(d) presents the typical TEM image of subsurface damage at middle discharge energy in the EDDG process. The subsurface structure composed of SiC grains, the remaining $\mathrm{Si}$, and their boundaries, is shown in Fig. 11 (b). A distinctive damage layer was observed beneath the machined surface. To further investigate the subsurface damage induced by the interaction between EDM and diamond grinding, two regions, $c$ and $d$, were selected at locations close to the EDM and grinding zones, respectively. In region $c$, microcracks and voids were found in the damage layer. The resolidified material protruded from the ground surface because EDM played a more important role than diamond grinding in this region, as shown in Fig. 11 (c). Furthermore, strain contours only occurred in the Si phase directly beneath the damage layer. This is because the bulk material was subjected to the thermal effect but with less 
This is a peer-reviewed, accepted author manuscript of the following research article: Rao, X., Zhang, F.,

Lu, Y., Luo, X., \& Chen, F. (Accepted/In press). Surface and subsurface damage of reactionbonded silicon carbide induced by electrical discharge diamond grinding. International Journal of Machine Tools and Manufacture. https://doi.org/10.1016/j.ijmachtools.2020.103564

mechanical force. However, high-density dislocation and microcracks were observed in the upper part of the SiC grains beneath the ground surface in region $d$, as shown in Fig. 11 (d), whereas numerous dislocations and stacking faults were generated in the low part of the $\mathrm{SiC}$ grains. This is attributed to the increase in the role of diamond grinding in this region. The results reveal a different influence of EDM and diamond grinding on the subsurface damage at different locations.

Therefore, a thick damage layer was formed in the less-thermally affected zone, as shown in Fig. 12 (a). Remarkable voids were observed in the subsurface of the lessthermally affected zone, which are attributed to the brittle fracture of the material under the diamond grinding action, indicating that diamond grinding was relatively unaffected by EDM in this zone. Thus, a shallower critical depth was obtained according to Eq. (10). The brittle regime dominated the material removal of the $\mathrm{RB}-\mathrm{SiC}$ and led to a thick damage layer with a thickness of $453 \mathrm{~nm}$. However, the discharge energy also plays an important role on the subsurface damage according to Eq. (7). Fig. 12 (b)-(d) presents the influence of discharge energy on subsurface damage. The thickness of the damage layer initially decreased and then increased with the increase in discharge energy. This is attributed to the brittle material removal at the lowest discharge energy and the excessive thermal stress at the highest discharge energy. The discharge energy transferred to the workpiece promoted the ductile removal of material, resulting in the decrease in brittle facture. Thus, a damage layer with thickness of $265 \mathrm{~nm}$ was formed at the lowest discharge energy. Additionally, a proper discharge energy resulted in 
This is a peer-reviewed, accepted author manuscript of the following research article: Rao, X., Zhang, F., Lu, Y., Luo, X., \& Chen, F. (Accepted/In press). Surface and subsurface damage of reactionbonded silicon carbide induced by electrical discharge diamond grinding. International Journal of Machine Tools and Manufacture. https://doi.org/10.1016/j.ijmachtools.2020.103564

protruded and active diamond grits in the grinding wheel. According to Eqs. (8) and (9), $a_{g m}$ increased when the active diamond grits increased. Therefore, the subsurface damage induced by EDM decreased owing to increase of $h_{p}$ and decrease of $a_{g}$ according to Eq. (7). The thickness of the damage layer decreased to $191 \mathrm{~nm}$ at the middle discharge energy.
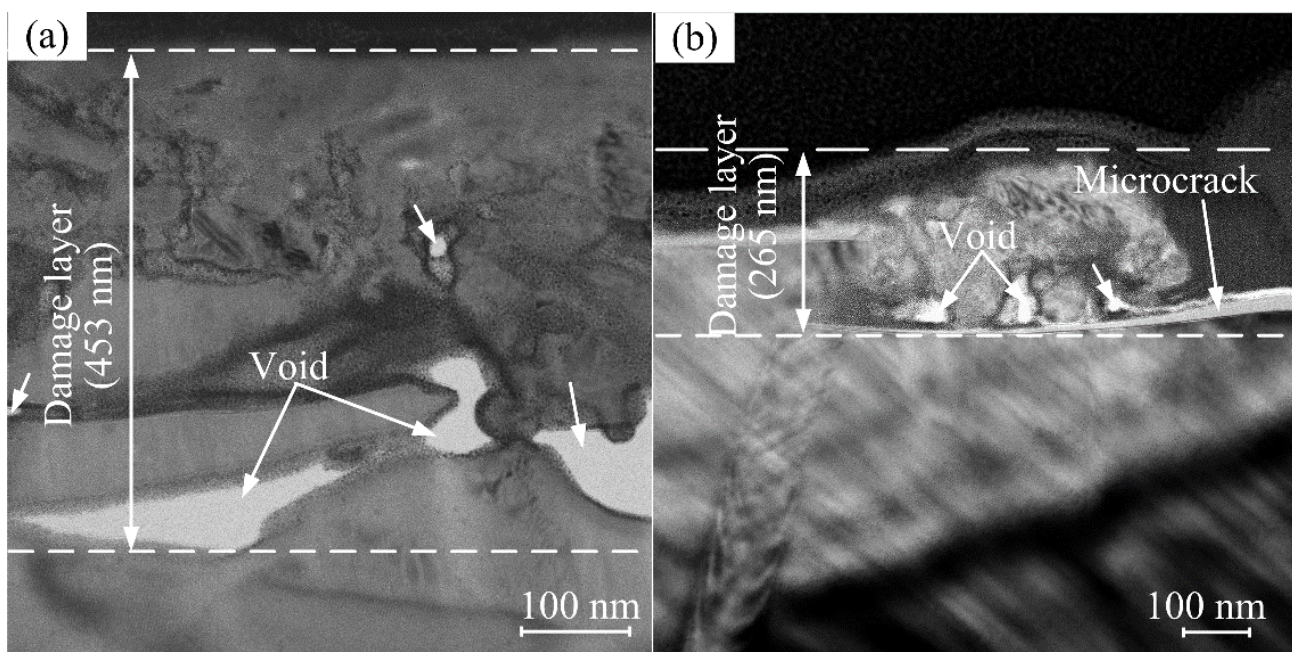

(c)

(d)
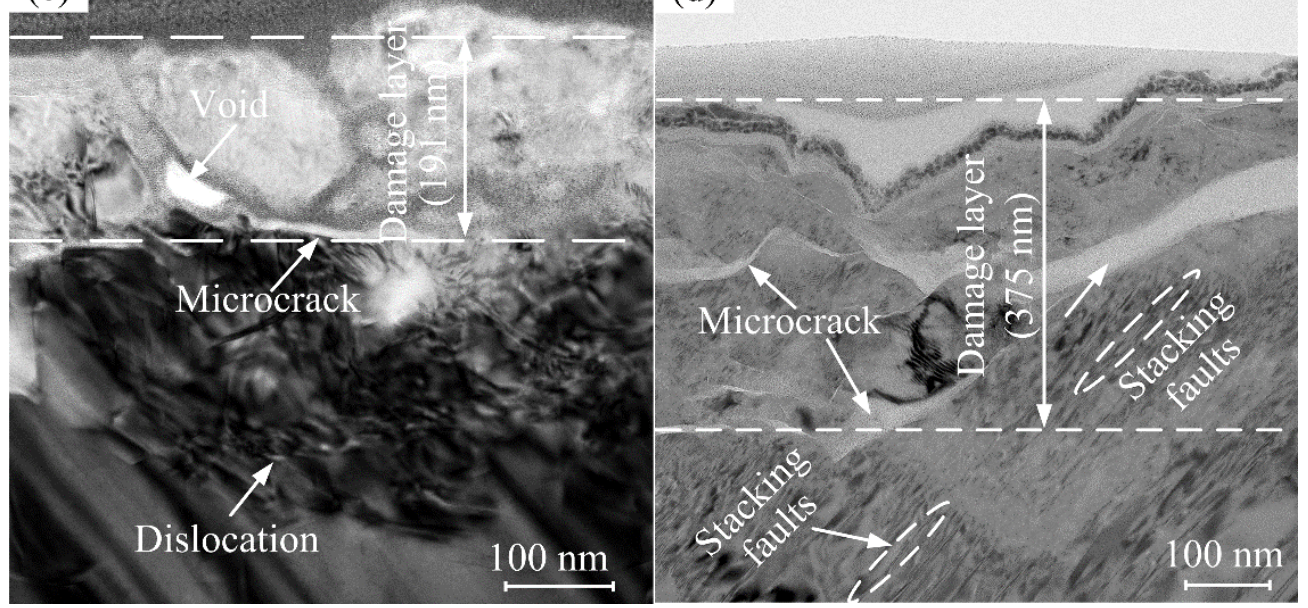

Fig. 12 Subsurface damage at different conditions. (a) In the less-thermally affected zone and at discharge energy of (b) $U=70 \mathrm{~V}$, Pulse $_{o n}=10 \mu \mathrm{s}$, (c) $U=100 \mathrm{~V}$, Pulse on $=$ $50 \mu \mathrm{s}$, and (d) $U=140 \mathrm{~V}$, Pulse $_{o n}=90 \mu \mathrm{s}$.

However, an excessive discharge energy led to a large amount of thermal damage, along 
This is a peer-reviewed, accepted author manuscript of the following research article: Rao, X., Zhang, F.,

Lu, Y., Luo, X., \& Chen, F. (Accepted/In press). Surface and subsurface damage of reactionbonded silicon carbide induced by electrical discharge diamond grinding. International Journal of Machine Tools and Manufacture. https://doi.org/10.1016/j.ijmachtools.2020.103564

with excessive dressing of the grinding wheel [33]. As a result, the damage layer increased to $375 \mathrm{~nm}$ at the highest discharge energy owing to decrease of $h_{p}$ and increase of $a_{g}$. Beneath the damage layer, the microstructure of the SiC grains exhibited no evident defects at the lowest discharge energy (Fig. 12 (b)), whereas distinguishable dislocation was observed at the middle discharge energy (Fig. 12 (c)), and numerous stacking faults were observed at the highest discharge energy (Fig. 12 (d)). It indicates that EDM can facilitate the ductile performance of diamond grits with the increase in discharge energy as plastic deformation of the material is caused by the generation and motion of dislocations.

\subsection{Elemental composition of subsurface}

Fig. 13 shows the element distributions of both pristine RB-SiC and the less-thermally affected zone. The elements $\mathrm{C}, \mathrm{Si}$, and $\mathrm{O}$ were uniformly distributed in the pristine $\mathrm{RB}$ $\mathrm{SiC}$, except for a higher concentration of $\mathrm{Si}$ in some regions owing to the remaining $\mathrm{Si}$, as indicated by the arrows in Fig. 13 (a1). The concentration of $\mathrm{C}$ was low, indicating that there was not $\mathrm{C}$ in simple substance in the pristine $\mathrm{RB}-\mathrm{SiC}$. Therefore, it was considered that $\mathrm{C}$ was generated in the EDDG process if a high concentration of $\mathrm{C}$ was detected on the cross section of the TEM specimens. A similar element distribution was found in the less-thermally affected zone, as shown in Fig. 13 (b1)-(b4). It reveals that pure diamond grinding also did not lead to decomposition of $\mathrm{SiC}$ into $\mathrm{C}$ in the subsurface. Moreover, the distribution of the $\mathrm{O}$ element indicated that almost no oxidation occurred in pristine $\mathrm{RB}-\mathrm{SiC}$ and the less-thermally affected zone. 
This is a peer-reviewed, accepted author manuscript of the following research article: Rao, X., Zhang, F., Lu, Y., Luo, X., \& Chen, F. (Accepted/In press). Surface and subsurface damage of reactionbonded silicon carbide induced by electrical discharge diamond grinding. International Journal of Machine Tools and Manufacture. https://doi.org/10.1016/j.ijmachtools.2020.103564

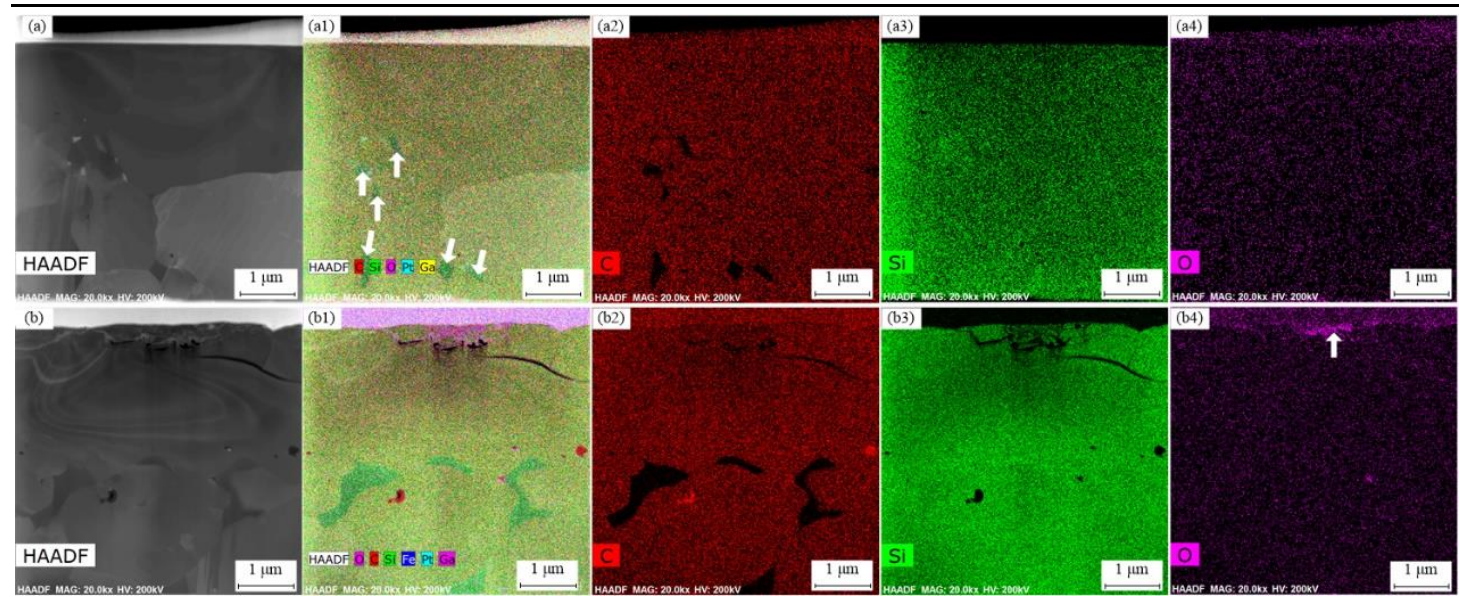

Fig. 13 STEM images and EDS mapping images of cross sections prepared from pristine RB-SiC and the less-thermally affected zone. (a) STEM image of pristine RBSiC, (a1)-(a4) elements $\mathrm{C}, \mathrm{Si}$, and $\mathrm{O}$ distributed in pristine RB-SiC, (b) STEM image of the less-thermally affected zone, and (b1)-(b4) elements $\mathrm{C}, \mathrm{Si}$, and $\mathrm{O}$ distributed in the less-thermally affected zone.

Fig. 14 shows the element distributions of the cross-sectional specimen at different discharge-energy levels. At the lowest discharge energy, C and Si were distributed uniformly in the $\mathrm{SiC}$ grains beneath the damage layer, whereas $\mathrm{C}, \mathrm{O}$, and $\mathrm{Fe}$ exhibited a relatively high concentration in the damage layer induced by the interaction between EDM and diamond grinding, as shown in Fig. 14 (a1), (a3) and (a4). It reveals that part of $\mathrm{SiC}$ was decomposed and oxidation occurred in the damage layer at the lowest discharge energy. However, the decomposition of SiC only occurred in the damage layer. The Fe detected in the damage layer was attributed to discharge-induced erosion of the iron bond of the grinding wheel, as shown in Fig. 14 (a4). 
This is a peer-reviewed, accepted author manuscript of the following research article: Rao, X., Zhang, F., Lu, Y., Luo, X., \& Chen, F. (Accepted/In press). Surface and subsurface damage of reactionbonded silicon carbide induced by electrical discharge diamond grinding. International Journal of Machine Tools and Manufacture. https://doi.org/10.1016/j.ijmachtools.2020.103564

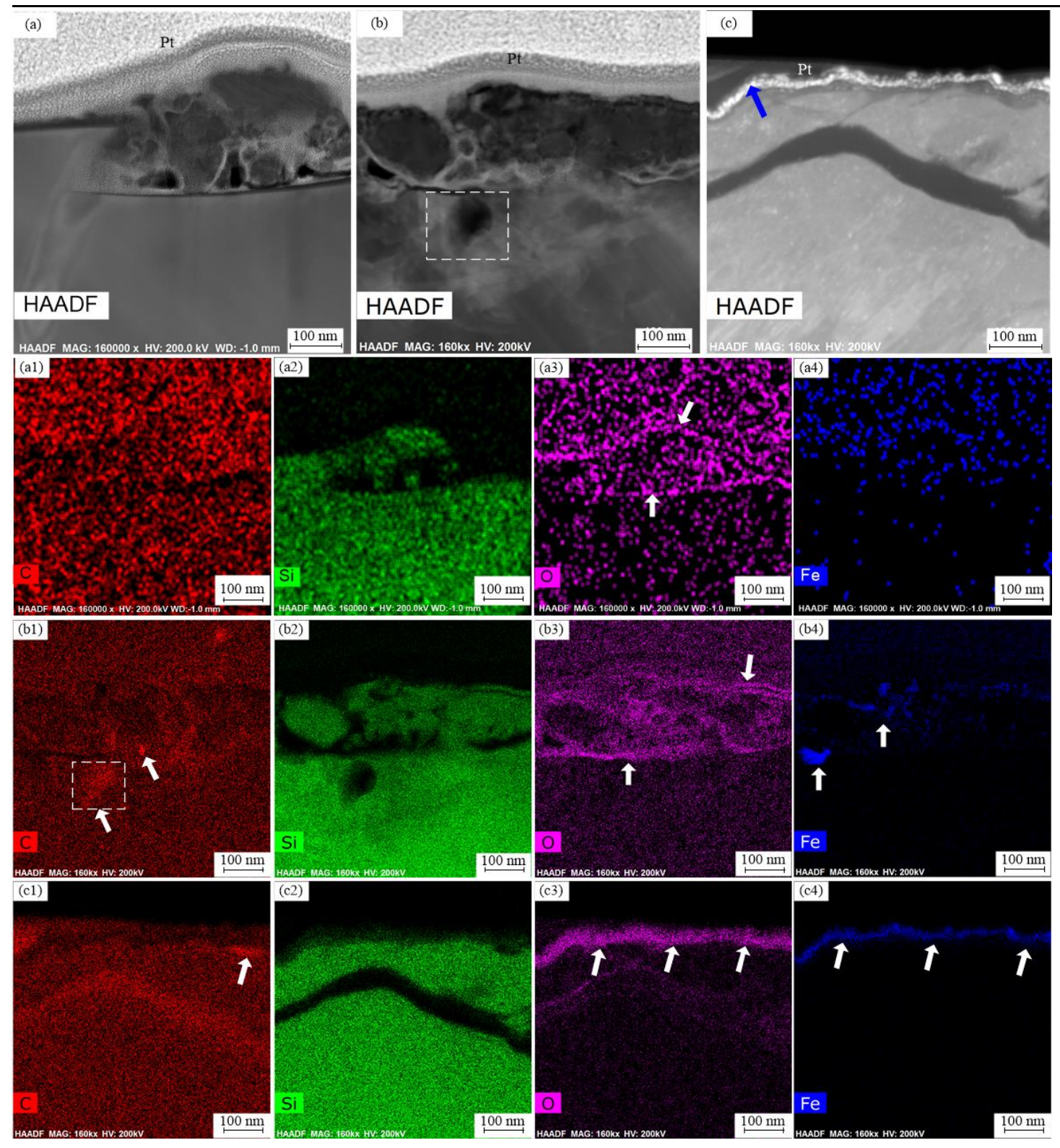

Fig. 14 STEM and EDS images of the cross-sectional specimen at different dischargeenergy levels. (a) STEM image at $U=70 \mathrm{~V}$, Puls $_{\text {on }}=10 \mu \mathrm{s}$, (b) STEM image at $U=$ $100 \mathrm{~V}$, Pulse $_{o n}=50 \mu \mathrm{s}$, and (c) STEM image at $U=140 \mathrm{~V}$, Pulse $_{o n}=90 \mu \mathrm{s}$; (a1)-(a4) distributions of $\mathrm{C}, \mathrm{Si}, \mathrm{O}$, and Fe elements for (a), (b1)-(b4) distributions of C, Si, O, and Fe elements for (b), and (c1)-(c4) distributions of C, Si, O, and Fe elements for (c). At the middle discharge energy, high concentrations of $\mathrm{C}$ and $\mathrm{O}$ and low concentration of Si were observed in the damage layer, as shown in Fig. 14 (b1)-(b3). It indicates that 
This is a peer-reviewed, accepted author manuscript of the following research article: Rao, X., Zhang, F.,

Lu, Y., Luo, X., \& Chen, F. (Accepted/In press). Surface and subsurface damage of reactionbonded silicon carbide induced by electrical discharge diamond grinding. International Journal of Machine Tools and Manufacture. https://doi.org/10.1016/j.ijmachtools.2020.103564

more $\mathrm{SiC}$ was decomposed and $\mathrm{Si}$ was evaporated. Oxidization was also generated in the damage layer due to EDM. However, a high concentration of C was also observed in the $\mathrm{SiC}$ grain beneath the damage layer, as marked by the white dotted box in Fig. 14 (b) and (b1). It indicates decomposition of the $\mathrm{SiC}$ beneath the damage layer due to more discharge energy transferred to the bulk material. Moreover, Fe was distributed with higher concentration on the upper surface of the damage layer, indicating an increase in the discharge-induced erosion of the iron bond.

Similarly, high $\mathrm{C}$ concentration was observed in a large area at the highest discharge energy, as shown in Fig. 14 (c1). This is attributed to more discharge energy transferred to the bulk material, causing more $\mathrm{SiC}$ decomposed into C. However, a uniform layer with high concentrations of $\mathrm{O}$ and Fe was formed on the ground surface, as shown in Fig. 14 (c3) and (c4). It indicates the increased discharge-induced erosion of iron bonds and the increased oxidation at the highest discharge energy.

Notably, the distribution of Fe detected in this work was referred to material migration in previous works $[12,20,34]$. In EDDG, discharge sparks are generated in the gap between the RB-SiC sample and the iron bond of the grinding wheel, causing melting and evaporation of both $\mathrm{RB}-\mathrm{SiC}$ and the iron bond. Therefore, melting and evaporation of the iron bond also increased with the increase in discharge energy. The melted iron bond migrates toward and is deposited on the machined surface of RB-SiC. Simultaneously, the excessive dressing of the grinding wheel led to incomplete removal of the material migration at the highest discharge energy. As a result, an oxidized layer 
This is a peer-reviewed, accepted author manuscript of the following research article: Rao, X., Zhang, F.,

Lu, Y., Luo, X., \& Chen, F. (Accepted/In press). Surface and subsurface damage of reactionbonded silicon carbide induced by electrical discharge diamond grinding. International Journal of Machine Tools and Manufacture. https://doi.org/10.1016/j.ijmachtools.2020.103564

containing the Fe element was formed at the highest discharge energy.

\subsection{Nanostructure change of subsurface}

The region $A$ marked in Fig. 11 (b) was selected to examine the nanostructure changes under the interaction between EDM and diamond grinding, as shown in Fig. 15 (a). Four HRTEM images taken from the damage layer and beneath it are displayed in Fig. 15 (b)-(e). To identify the nanostructure of the $\mathrm{SiC}$ in the tested region, the corresponding FFT patterns were also conducted. The bright region labelled $B$ in Fig. 15 (a) was identified as a carbonaceous component surrounded by $\mathrm{SiC}$, as described in Section 5.2, according to the analysis of the element distribution in Fig. 14 (b1)-(b4), which was further confirmed by HRTEM.

According to the discussion in section 5.1, regions 1 and 2 are located in the damage layer. However, region 1 is closer to the EDM zone than region 2. The HRTEM images reveal many fine $\mathrm{SiC}$ grains in region 1, whereas larger $\mathrm{SiC}$ grains are found in region 2, as shown in Fig. 15 (b) and (c). Owing to the semi-circular isotherm distribution in the bulk material induced by EDM [35], the SiC grain preferred to form fine grains in region 1 under diamond grinding. With obvious diffraction rings that occurred in $6 \mathrm{H}-$ $\mathrm{SiC}$ (0006), the FFT patterns in the lower left-hand corner further reveal the polycrystalline/nanocrystalline structures of the $\mathrm{SiC}$ in the damage layer. In region 2 , diamond grinding played a more important role than EDM, resulting in the difference in diffraction rings. 
This is a peer-reviewed, accepted author manuscript of the following research article: Rao, X., Zhang, F., Lu, Y., Luo, X., \& Chen, F. (Accepted/In press). Surface and subsurface damage of reactionbonded silicon carbide induced by electrical discharge diamond grinding. International Journal of Machine Tools and Manufacture. https://doi.org/10.1016/j.ijmachtools.2020.103564

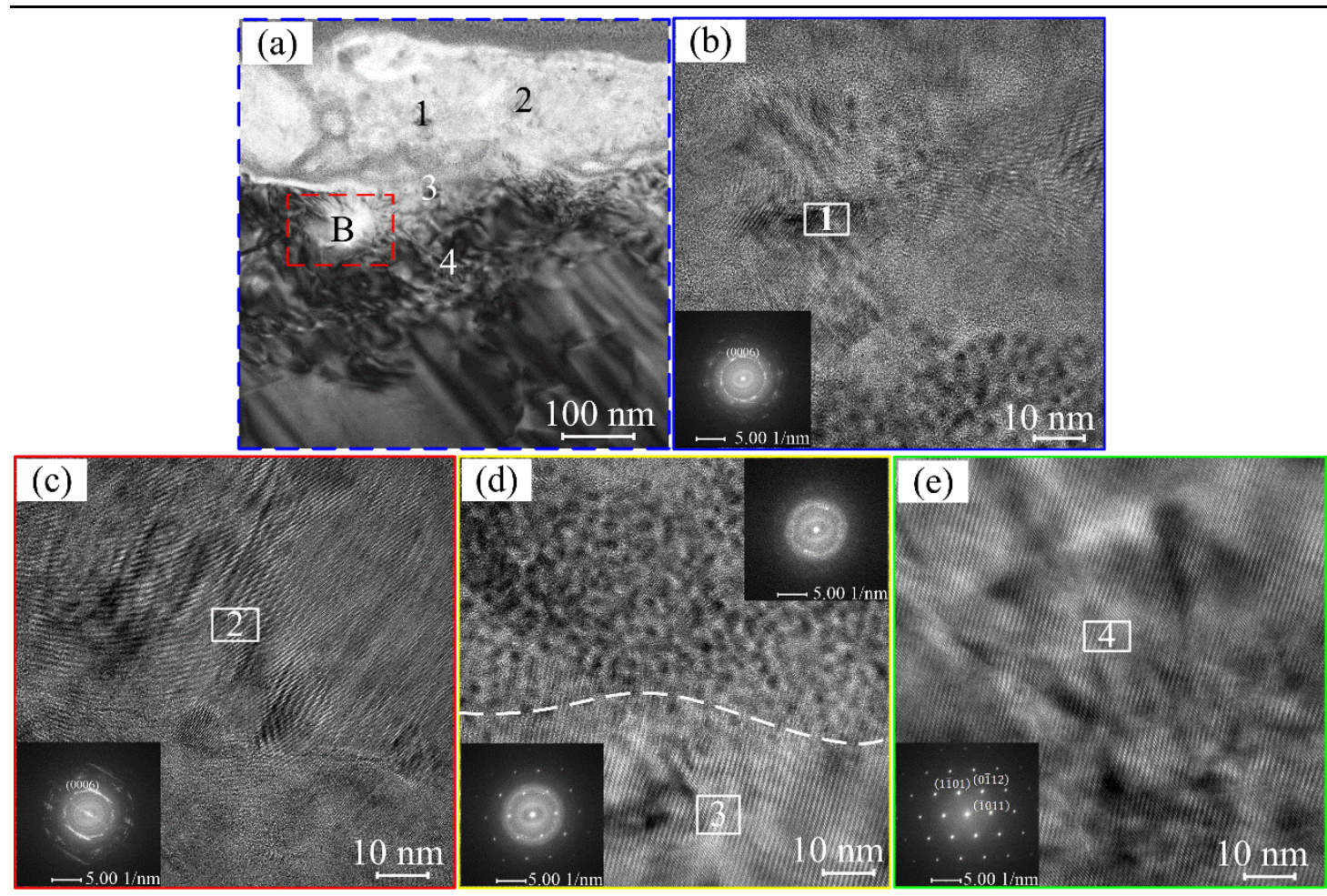

Fig. 15 TEM and HRTEM images of region $A$. (a) TEM image, (b)-(e) HRTEM images of regions 1, 2, 3, and 4 and their corresponding FFT patterns.

In region 3, two distinct nanostructures were detected at the interface between the damage layer and the bulk material, as shown in Fig. 15 (d). Only polycrystalline/nanocrystalline structures are observed at the upper part of Fig. 15 (d), which is mainly attributed to the migration of the Pt deposited on the ground surface during the FIB process. However, a relatively regular diffraction is observed at the lower part of Fig. 15 (d). The FFT pattern shows a strong lattice diffraction and weak rings, indicating crystal and polycrystalline structures in this region. The crystal structure indicates less influence induced by EDM in the bulk material. Therefore, only lattice diffraction of crystal $\mathrm{SiC}$ is observed in the deeper dislocation region 4 , as shown in Fig. 15 (e). 
This is a peer-reviewed, accepted author manuscript of the following research article: Rao, X., Zhang, F.,

Lu, Y., Luo, X., \& Chen, F. (Accepted/In press). Surface and subsurface damage of reactionbonded silicon carbide induced by electrical discharge diamond grinding. International Journal of Machine Tools and Manufacture. https://doi.org/10.1016/j.ijmachtools.2020.103564

As mentioned above, the region $B$ marked in Fig.15 (a) was detected by HRTEM and

FFT to determine the nanostructure of the decomposed $\mathrm{C}$ and the $\mathrm{SiC}$ surrounding it, as shown in Fig. 16. At location 1 and 2, crystal and polycrystalline structures of the $\mathrm{SiC}$ phases were identified according to the FFT patterns. However, more small bright spots are dispersed in the regular crystal diffraction at location 2, which is attributed to the decomposed $\mathrm{C}$ embedded in the polycrystalline $\mathrm{SiC}$ under the increasing performance of diamond grinding. The FFT pattern shows fuzzy rings along with a weak ring, indicating the mainly amorphous structure of the decomposed C accompanied with several regular structures such as graphite sheets. Therefore, the ribbons beneath location 3 were identified as graphite sheets with a lattice spacing of $0.359 \mathrm{~nm}$. The deviation of the lattice spacing from that of the ideal hexagonal graphite structure $(0.35 \mathrm{~nm}[36])$ is attributed to the disordered graphite sheets. This result agrees with the Raman spectra of the D peak mentioned in Section 4.2.

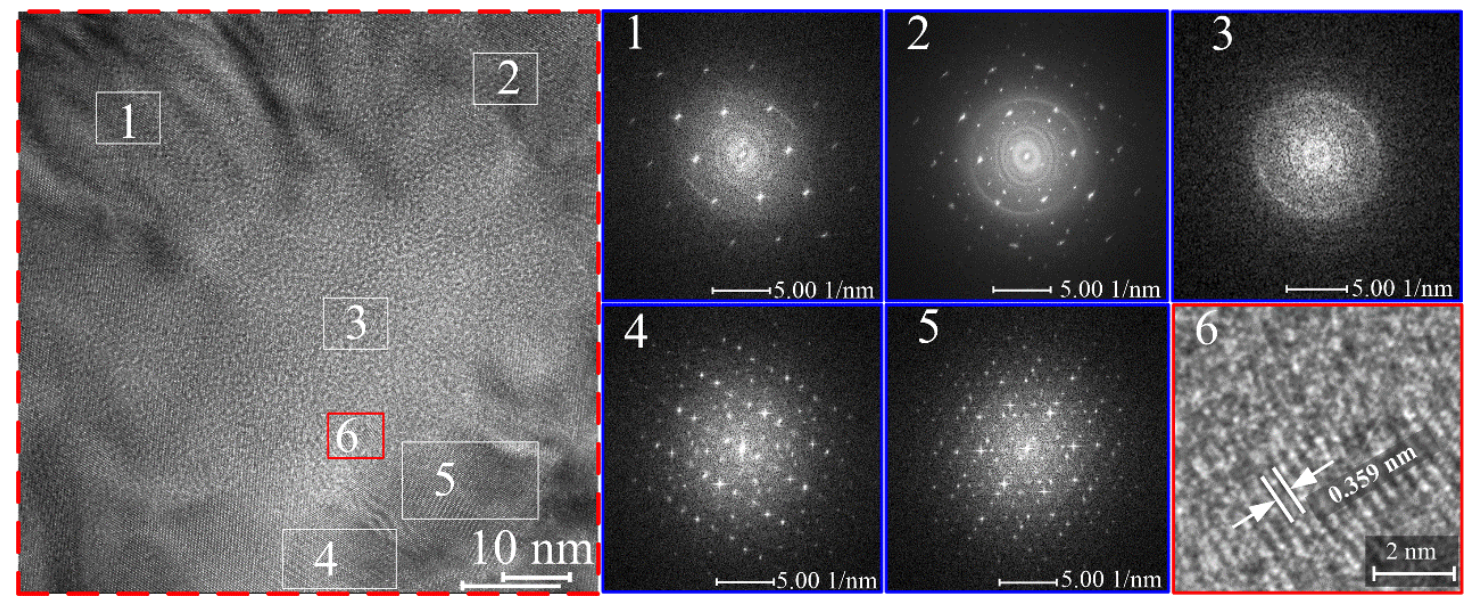

Fig. 16 HRTEM image and FFT patterns of region $B$. The nanostructure of the carbonaceous component at location 3 was surrounded by the nanostructures of the $\mathrm{SiC}$ phases at locations 1, 2, 4, and 5. The magnified HRTEM image shows $\mathrm{C}$ ribbons at 
This is a peer-reviewed, accepted author manuscript of the following research article: Rao, X., Zhang, F.,

Lu, Y., Luo, X., \& Chen, F. (Accepted/In press). Surface and subsurface damage of reactionbonded silicon carbide induced by electrical discharge diamond grinding. International Journal of Machine Tools and Manufacture. https://doi.org/10.1016/j.ijmachtools.2020.103564

location 6.

However, the hexagonal graphite crystal formed needs a higher temperature. At location 6, the temperature was lower than that at location 3 owing to isotherm distribution induced by EDM. Therefore, the mechanical pressure induced by diamond grinding is responsible for the formation of graphite sheets at location 6 . In the grinding of RB$\mathrm{SiC}$, the high pressure has been reported to result in phase transformation of $\mathrm{SiC}$ and $\mathrm{C}$ components $[37,38]$. As a result, abundant twins and nanocrystalline structures of $\mathrm{SiC}$ were formed at locations 4 and 5 .

\section{Conclusions}

The surface and subsurface damage induced by the interactions between EDM and diamond grinding in EDDG of RB-SiC was investigated. The changes in the microstructure and phase component at three discharge-energy levels (characterized by different open-circuit voltages and pulse-on times) were examined. To provide evidence for the subsurface damage and microstructure changes induced by the EDDG process, comparative tests were performed on a pristine $\mathrm{RB}-\mathrm{SiC}$ sample. According to the results, the following conclusions are drawn:

(1) Two distinct zones, i.e., the EDM and grinding zones, were identified on the ground surface after EDDG of the RB-SiC, and they exhibited different topographies. The degree of ductile removal of the material in the grinding zone depended on the discharge-energy level. As the discharge energy increased, the grinding track transitioned from brittle fracture to plastic deformation and then to oxidation. 
This is a peer-reviewed, accepted author manuscript of the following research article: Rao, X., Zhang, F.,

Lu, Y., Luo, X., \& Chen, F. (Accepted/In press). Surface and subsurface damage of reactionbonded silicon carbide induced by electrical discharge diamond grinding. International Journal of Machine Tools and Manufacture. https://doi.org/10.1016/j.ijmachtools.2020.103564

(2) The decomposition of SiC into C occurred at the boundary and in the EDM zone. With the low evaporation temperature, the evaporation of Si led the decomposed C to remain. The Raman spectra of the $\mathrm{Si}, \mathrm{SiC}$, and $\mathrm{C}$ components indicated the changes of the residual stress and microstructure under the interactions between EDM and diamond grinding at different locations. The Raman spectra of the $\mathrm{C}$ components exhibited an increase in the D peak, indicating that there was a larger amount of decomposed $\mathrm{C}$ with a disordered structure with an increase in the discharge energy.

(3) Owing to the different roles that EDM and diamond grinding played at different locations, the damage layer and bulk material beneath it showed different characteristics. Dislocation and stacking faults occurred in the region close to the grinding zone. As a result, a thick damage layer was obtained in the less-thermally affected zone. Owing to the facilitated ductile removal of the material and the dressing effect induced by EDM, the thickness of the damage layer decreased with the increasing discharge energy. The thickness increased again at the highest discharge energy owing to the heavy thermal damage and the excessive dressing of the grinding wheel. However, it was still smaller than that in the less-thermally affected zone.

(4) Compared with the element distributions in pristine RB-SiC and the less-thermally affected zone, an EDS mapping analysis revealed that the decomposed $\mathrm{C}$ caused by the discharge energy transferred to the subsurface. Moreover, the high concentration 
This is a peer-reviewed, accepted author manuscript of the following research article: Rao, X., Zhang, F.,

Lu, Y., Luo, X., \& Chen, F. (Accepted/In press). Surface and subsurface damage of reaction-

bonded silicon carbide induced by electrical discharge diamond grinding. International Journal of Machine Tools and Manufacture. https://doi.org/10.1016/j.ijmachtools.2020.103564

of Fe indicated the migration of iron bonds of the grinding wheel during the EDDG

process. The area of the decomposed $\mathrm{C}$ and material migration tended to increase with the discharge energy.

(5) From the damage layer to the bulk material of $\mathrm{SiC}$, the nanostructure of the $\mathrm{SiC}$ phase changed from polycrystalline to crystalline in the subsurface. The decomposed $\mathrm{C}$ with an amorphous structure was detected beneath the damage layer owing to the high temperature induced by EDM. At a lower-temperature location, graphite sheets were formed because of the high mechanical pressure induced by diamond grinding. The results indicate the effects of the interaction between EDM and diamond grinding on the subsurface damage in EDDG of RB-SiC. The isotherm distribution induced by EDM explained the nanocrystalline and twin structures of SiC surrounding the $\mathrm{C}$ components.

\section{References}

[1] X. Wang, X. Zhang, Theoretical study on removal rate and surface roughness in grinding a RB-SiC mirror with a fixed abrasive, Appl. Opt. 48 (2009) 904-910.

[2] F.J. Chen, S.H. Yin, H. Huang, H. Ohmori, Y. Wang, Y.F. Fan, Y.J. Zhu, Profile error compensation in ultra-precision grinding of aspheric surfaces with onmachine measurement, Int. J. Mach. Tools Manuf. 50 (2010) 480-486.

[3] L. Liu, F. Zhang, Prediction model of form error influenced by grinding wheel wear in grinding process of large-scale aspheric surface with $\mathrm{SiC}$ ceramics, Int. J. Adv. Manuf. Technol. 88 (2017) 899-906. 
This is a peer-reviewed, accepted author manuscript of the following research article: Rao, X., Zhang, F.,

Lu, Y., Luo, X., \& Chen, F. (Accepted/In press). Surface and subsurface damage of reaction-

bonded silicon carbide induced by electrical discharge diamond grinding. International Journal of Machine Tools and Manufacture. https://doi.org/10.1016/j.ijmachtools.2020.103564

[4] J. Xie, Q. Li, J.X. Sun, Y.H. Li, Study on ductile-mode mirror grinding of SiC ceramic freeform surface using an elliptical torus-shaped diamond wheel, J. Mater. Process. Technol. 222 (2015) 422-433.

[5] X. Rao, F. Zhang, C. Li, Y. Li, Experimental investigation on electrical discharge diamond grinding of RB-SiC ceramics, Int. J. Adv. Manuf. Technol. 94 (2018) 2751-2762.

[6] P. Koshy, V.K. Jain, G.K. Lal, Mechanism of material removal in electrical discharge diamond grinding, Int. J. Mach. Tools Manuf. 36 (1996) 1173-1185.

[7] M.K. Satyarthi, P.M. Pandey, Modeling of material removal rate in electric discharge grinding process, Int. J. Mach. Tools Manuf. 74 (2013) 65-73.

[8] K.M. Shu, G.C. Tu, Study of electrical discharge grinding using metal matrix composite electrodes, Int. J. Mach. Tools Manuf. 43 (2003) 845-854.

[9] P. Koshy, V.K. Jain, G.K. Lal, Grinding of cemented carbide with electrical spark assistance, J. Mater. Process. Technol. 72 (1997) 61-68.

[10] S. Clijsters, K. Liu, D. Reynaerts, B. Lauwers, EDM technology and strategy development for the manufacturing of complex parts in SiSiC, J. Mater. Process. Technol. 210 (2010) 631-641.

[11] K. Albiński, K. Musioł, A. Miernikiewicz, S. Łabuz, M. Małota, The temperature of a plasma used in electrical discharge machining, Plasma Sources Sci. Technol. 5 (1996) 736-742.

[12] P.J. Liew, J. Yan, T. Kuriyagawa, Fabrication of deep micro-holes in reaction- 
This is a peer-reviewed, accepted author manuscript of the following research article: Rao, X., Zhang, F., Lu, Y., Luo, X., \& Chen, F. (Accepted/In press). Surface and subsurface damage of reactionbonded silicon carbide induced by electrical discharge diamond grinding. International Journal of Machine Tools and Manufacture. https://doi.org/10.1016/j.ijmachtools.2020.103564

bonded $\mathrm{SiC}$ by ultrasonic cavitation assisted micro-EDM, Int. J. Mach. Tools Manuf. 76 (2014) 13-20.

[13] Y.H. Liu, R. Ji, Q. Li, L. Yu, X. Li, Electric discharge milling of silicon carbide ceramic with high electrical resistivity, Int. J. Mach. Tools Manuf. 48 (2008) 1504-1508.

[14] R. Ji, Y. Liu, Y. Zhang, F. Wang, Machining performance of silicon carbide ceramic in end electric discharge milling, Int. J. Refract. Met. Hard Mater. 29 (2011) 117-122.

[15] Y. Zhao, M. Kunieda, K. Abe, Study of EDM cutting of single crystal silicon carbide, Precis. Eng. 38 (2014) 92-99.

[16] Y. Ishikawa, Y.Z. Yao, Y. Sugawara, K. Sato, Y. Okamoto, N. Hayashi, B. Dierre, K. Watanabe, T. Sekiguchi, Comparison of slicing-induced damage in hexagonal $\mathrm{SiC}$ by wire sawing with loose abrasive, wire sawing with fixed abrasive, and electric discharge machining, Jpn. J. Appl. Phys. 53 (2014) 071301-1-11.

[17] C.J. Luis, I. Puertas, G. Villa, Material removal rate and electrode wear study on the EDM of silicon carbide, J. Mater. Process. Technol. 164-165 (2005) 889896.

[18] K. Kumar Saxena, A. Suman Srivastava, S. Agarwal, Experimental investigation into the micro-EDM characteristics of conductive SiC, Ceram. Int. 42 (2016) $1597-1610$. 
This is a peer-reviewed, accepted author manuscript of the following research article: Rao, X., Zhang, F.,

Lu, Y., Luo, X., \& Chen, F. (Accepted/In press). Surface and subsurface damage of reaction-

bonded silicon carbide induced by electrical discharge diamond grinding. International Journal

of Machine Tools and Manufacture. https://doi.org/10.1016/j.ijmachtools.2020.103564

[19] T.H. Tan, J. Yan, Atomic-scale characterization of subsurface damage and structural changes of single-crystal silicon carbide subjected to electrical discharge machining, Acta Mater. 123 (2017) 362-372.

[20] P.J. Liew, J. Yan, T. Kuriyagawa, Experimental investigation on material migration phenomena in micro-EDM of reaction-bonded silicon carbide, Appl. Surf. Sci. 276 (2013) 731-743..

[21] J. Yan, T.H. Tan, Sintered diamond as a hybrid EDM and grinding tool for the micromachining of single-crystal SiC, CIRP Ann. - Manuf. Technol. 64 (2015) 221-224.

[22] B. Zhang, X.L. Zheng, H. Tokura, M. Yoshikawa, Grinding induced damage in ceramics, J. Mater. Process. Technol. 132 (2003) 353-364.

[23] S. Agarwal, P.V. Rao, Experimental investigation of surface/subsurface damage formation and material removal mechanisms in SiC grinding, Int. J. Mach. Tools Manuf. 48 (2008) 698-710.

[24] X. Rao, F. Zhang, X. Luo, F. Ding, Y. Cai, J. Sun, H. Liu, Material removal mode and friction behaviour of $\mathrm{RB}-\mathrm{SiC}$ ceramics during scratching at elevated temperatures, J. Eur. Ceram. Soc. 39 (2019) 3534-3545.

[25] H. XIA, M. Kunieda, N. Nishiwaki, Removal Amount Difference between Anode and Cathode in EDM Process., Int. J. Electical Mach. 1 (1996) 45-52.

[26] X. Yue, X. Yang, J. Tian, Z. He, Y. Fan, Thermal,mechanical and chemical material removal mechanism of carbon fiber reinforced polymers in electrical 
This is a peer-reviewed, accepted author manuscript of the following research article: Rao, X., Zhang, F.,

Lu, Y., Luo, X., \& Chen, F. (Accepted/In press). Surface and subsurface damage of reaction-

bonded silicon carbide induced by electrical discharge diamond grinding. International Journal

of Machine Tools and Manufacture. https://doi.org/10.1016/j.ijmachtools.2020.103564

discharge machining, Int. J. Mach. Tools Manuf. 133 (2018) 4-17.

[27] Y. Zhang, C. Li, H. Ji, X. Yang, M. Yang, D. Jia, X. Zhang, R. Li, J. Wang, Analysis of grinding mechanics and improved predictive force model based on material-removal and plastic-stacking mechanisms, Int. J. Mach. Tools Manuf. 122 (2017) 81-97.

[28] C. Li, X. Li, Y. Wu, F. Zhang, H. Huang, Deformation mechanism and force modelling of the grinding of YAG single crystals, Int. J. Mach. Tools Manuf. 143 (2019) 23-37.

[29] T.G. Bifano, T.A. Dow, R.O. Scattergood, Ductile-Regime Grinding : A New Technology for Machining Brittle Materials, Trans. ASME. 113 (1991) 184-189.

[30] Y. Kang, Y. Qiu, Z. Lei, A robust method to measure residual stress in microstructure, Optoelectron. Lett. 3 (2007) 126-128.

[31] Y. Kang, Y. Qiu, Z. Lei, M. Hu, An application of Raman spectroscopy on the measurement of residual stress in porous silicon, Opt. Lasers Eng. 43 (2005) $847-855$.

[32] S. Nakashima, H. Harima, Raman Investigation of SiC Polytypes, Phys. Status Solidi. 39 (1997) 39-64.

[33] Y.J. Lu, J. Xie, X.H. Si, Study on micro-topographical removals of diamond grain and metal bond in dry electro-contact discharge dressing of coarse diamond grinding wheel, Int. J. Mach. Tools Manuf. 88 (2015) 118-130.

[34] P.J. Liew, J. Yan, T. Kuriyagawa, Carbon nanofiber assisted micro electro 
This is a peer-reviewed, accepted author manuscript of the following research article: Rao, X., Zhang, F., Lu, Y., Luo, X., \& Chen, F. (Accepted/In press). Surface and subsurface damage of reactionbonded silicon carbide induced by electrical discharge diamond grinding. International Journal of Machine Tools and Manufacture. https://doi.org/10.1016/j.ijmachtools.2020.103564

discharge machining of reaction-bonded silicon carbide, J. Mater. Process. Technol. 213 (2013) 1076-1087.

[35] S.H. Yeo, W. Kurnia, P.C. Tan, Critical assessment and numerical comparison of electro-thermal models in EDM, J. Mater. Process. Technol. 203 (2008) 241251.

[36] S. Welz, M.J. McNallan, Y. Gogotsi, Carbon structures in silicon carbide derived carbon, J. Mater. Process. Technol. 179 (2006) 11-22.

[37] Q. Zhang, S. To, Q. Zhao, B. Guo, Amorphization and C segregation based surface generation of Reaction-Bonded SiC/Si composites under micro-grinding, Int. J. Mach. Tools Manuf. 95 (2015) 78-81.

[38] J. Ni, B. Li, Phase transformation in high-speed cylindrical grinding of SiC and its effects on residual stresses, Mater. Lett. 89 (2012) 150-152. 